\title{
Ni enfermedad, ni pecado, ni déficit. Barreras y facilitadores para estudiantes con discapacidad y estudiantes LGBTIQ+ en el sistema educativo colombiano
}

No sickness, no sin, no deficit. Barriers and facilitators for students with disabilities and LGBTIQ+ students in the Colombian education system

\section{Volumen 21, Número 2}

Mayo - Agosto

pp. 1-37

\section{Elena Marulanda Páez}

\section{Citar este documento según modelo APA}

Marulanda Páez, Elena. (2021). Ni enfermedad, ni pecado, ni déficit. Barreras y facilitadores para estudiantes con discapacidad y estudiantes LGBTIQ+ en el sistema educativo colombiano. Revista Actualidades Investigativas en Educación, 21(2), 1-37. Doi. 10.15517/aie.v21i2.46760 


\title{
Ni enfermedad, ni pecado, ni déficit. Barreras y facilitadores para estudiantes con discapacidad y estudiantes LGBTIQ+ en el sistema educativo colombiano
}

\author{
No sickness, no sin, no deficit. Barriers and facilitators for students with disabilities and \\ LGBTIQ+ students in the Colombian education system
}

\section{Elena Marulanda Páez}

\begin{abstract}
Resumen: Este artículo presenta los resultados de una revisión sistemática documental encaminada a determinar las barreras y facilitadores para el ingreso y permanencia en el sistema educativo colombiano de dos colectivos históricamente marginados de una educación de calidad en este país: estudiantes con discapacidad y niños, niñas y jóvenes LGBTIQ+. El estudio se desarrolló bajo una metodología cualitativa basada en el análisis de contenido de fuentes secundarias. Para alcanzar el propósito antes mencionado, se consultaron sistematizaciones de experiencias de aula e innovaciones educativas exitosas con alguno o los dos colectivos objeto de la investigación, desarrolladas entre los años 2016 y 2020. Así las cosas, se revisaron reportes de investigación tanto en artículos científicos, trabajos de pregrado y posgrado. Los trabajos incluidos tuvieron lugar en comunidades urbanas colombianas de distintas regiones del país y su elección siguió los principios de la declaración PRISMA. Para el colectivo con discapacidad, los hallazgos pusieron de manifiesto avances en cuanto a adaptaciones y ajustes curriculares tendientes a favorecer oportunidades de aprendizaje para esta población estudiantil, especialmente, en educación básica primaria. Una barrera que debe seguirse trabajando en educación secundaria y superior, en particular, tiene que ver con la ausencia de formación del profesorado y la prevalencia de falsas creencias sobre cómo aprenden las personas con discapacidad y sus posibilidades en la escuela. En lo que respecta al alumnado LGBTIQ+, se observó una brecha entre políticas institucionales que apoyan una educación para todos y todas, versus prácticas de convivencia que aún fomentan escenarios de marginación. Se identificaron diversas barreras ligadas a estereotipos sobre la orientación sexual y la identidad de género, así como ausencia de protocolos para mitigar las múltiples violencias que aún aquejan a estos colectivos.
\end{abstract}

Palabras clave: educación inclusiva, discapacidad, grupos LGBTIQ+, discriminación

\begin{abstract}
This article presents the results of a systematic documentary review aimed at determining the barriers and facilitators for the entry and stay in the Colombian education system of two groups historically marginalized from a quality education in this country: students with disabilities and LGBTIQ+ children. The study was developed under a qualitative methodology based on the content analysis of secondary sources. To achieve the aforementioned purpose, systematization of classroom experiences and successful educational innovations with one or both target groups of the research, developed between 2016 and 2020, were reviewed. The works included took place in Colombian urban communities in different regions of the country and their choice followed the principles of the PRISMA Declaration. For the group with disabilities, the findings showed advances in terms of adaptations and curricular adjustments aimed at encouraging learning opportunities for these students, especially in primary basic education. A barrier to continuing work in secondary and higher education, in particular, has to do with the lack of teacher training and the prevalence of false beliefs about how people with disabilities learn and their possibilities in school. With regard to LGBTIQ+ students, a gap was observed between institutional policies that support education for all, versus coexistence practices that still foster scenarios of marginalization. Various barriers linked to stereotypes about sexual orientation and gender identity were identified, as well as the absence of protocols to mitigate the multiple violence that still afflict these groups.
\end{abstract}

Key words: inclusive education, disability, LGBTIQ+ community, discrimination

${ }_{1}^{1}$ Profesora Asociada de la Pontificia Universidad Javeriana, Bogotá, Colombia. Magister en
Educación de la Pontificia Universidad Javeriana, Colombia y Doctora en Psicología por la
Universidad Autónoma de Madrid, España. Dirección electrónica:
emarulanda@javeriana.edu.co ORCID: https://orcid.org/0000-0002-4077-3484

Artículo recibido: 18 de noviembre, 2020

Enviado a corrección: 9 de marzo, 2021

Aprobado: 19 de abril, 2021

Los contenidos de este artículo están bajo una licencia Creative Commons 


\section{Introducción}

En Colombia, este nuevo siglo ha constituido una época de cambios significativos en materia de política pública para los colectivos de personas con discapacidad (en adelante, PCD) y con orientaciones sexuales e identidades de género diversas (en lo sucesivo, LGBTIQ ${ }^{2}{ }^{2}$. En línea con esta consideración, durante los últimos diez años se han aprobado importantes decretos que regulan, entre otros, el derecho a una educación inclusiva y de calidad, con especial atención a los requerimientos de estas dos poblaciones (v.gr., decreto 1066 de 2015, decreto 1421 de 2017, decreto 762 de 2018). Asimismo, diversos organismos estatales se han pronunciado en torno a la necesidad de garantizar que cualquier PcD o estudiante LGBTIQ+ reciba la libertad, el reconocimiento y las adaptaciones y ajustes que precisa para su pleno desarrollo en la escuela (Ministerio de Educación Nacional, [MEN], 2017a; Ramírez, 2017). Si bien, en el país se identifican experiencias significativas que dan cuenta de un ejercicio de inclusión y acompañamiento a estos colectivos, las prácticas educativas en los colegios y universidades colombianas deben continuar fortaleciéndose para acercarse aún más a los ideales que proponen estas normativas. En correspondencia con este argumento, todavía se vivencian escenarios de segregación y discriminación que impiden a niños, niñas y jóvenes con discapacidad y/o LGBTIQ+ culminar su paso por la educación básica, secundaria y superior (Marulanda y García-Cepero, 2019).

En este marco, la línea de investigación en Educación Inclusiva y Atención a la Diversidad de la Facultad de Educación de la Pontificia Universidad Javeriana (Colombia), en cabeza de su directora y de estudiantes de pre y posgrado interesados en estos temas, recabaron, entre los años 2016 y 2020, diversos tipos de estudios y análisis de experiencias educativas que permitieran entrever las barreras y facilitadores educativos para ambos colectivos, en lo que toca a su ingreso y permanencia en el sistema educativo formal colombiano. Se seleccionaron las PCD y estudiantes LGBTIQ+, dado que son aquellos a quienes los estamentos gubernamentales colombianos han prestado mayor atención en materia de lineamientos y orientaciones técnicas y pedagógicas en los últimos diez años (MEN, 2017a; Departamento Nacional de Planeación [DNP], 2015) y, pese a ello, continúan

\footnotetext{
2 A pesar de lo polémico de la sigla $\mathrm{LGBTIQ+}$, se empleará aquí tal y como se usa en el documento de Enfoque e Identidades de Género para los Lineamientos de la Política de Educación Superior Inclusiva, desarrollado por el Ministerio de Educación Nacional de Colombia (MEN) en 2018, según el cual en esta abreviatura se recogen "los derechos plenos de las personas lesbianas, gais, bisexuales, trans-generistas, intersexuales y queersexuales" ( $p$. 16) y de todos aquellos ciudadanos con orientaciones sexuales e identidades de género no hegemónicas, que no se sientan representados por los seis colectivos antes mencionados. Estos últimos se representan con el signo + .
} 
enfrentando importantes dificultades para acceder, permanecer y egresar del sistema educativo en sus distintos niveles.

Distintos trabajos han apuntado la relevancia de conocer las barreras y facilitadores que se proveen a estudiantes que pueden ser objeto de exclusión o marginación, en el marco de la educación inclusiva. El alumnado LGBTIQ+ y las personas con discapacidad forman parte de tales colectivos (Fernández, Fiuza y Zabalza, 2013; González, Martin y Poy, 2019; Mella, Díaz, Muñoz, Orrego y Rivera, 2014; Victoriano, 2017). Siguiendo a Rivas, Leite y Prados (2014), los resultados de estos estudios constituyen evidencias eseciales para generar oportunidades reales que favorezcan y promuevan el aprendizaje y bienestar de todo el estudiantado. Dado que los sistemas educativos de cada país comportan políticas y reglamentaciones gubernamentales distintas, se hace necesario contar con investigaciones acotadas a dichas características (Artiles, Kozleski y Waitoller, 2011).

En línea con lo antes expuesto, se realizó una revisión sistemática documental en la que se analizaron estudios empíricos y documentales de diversa índole. Dichos estudios incluyeron experiencias educativas tendientes a la plena inclusión en aulas de educación urbana en Colombia de PcD y comunidades LGTBIQ+, así como investigaciones con agentes de diferentes niveles educativos (v.gr., educación inicial, básica, media, técnica-tecnológica o superior) encaminadas a recoger percepciones, creencias, imaginarios, o buenas prácticas de enseñanza y aprendizaje con ambos grupos de estudiantes. De igual modo, se consideraron innovaciones educativas propuestas y/o probadas en aulas regulares del sistema educativo colombiano, cuya finalidad estuviera centrada en mejorar el acceso o la permanencia de PcD o del alumnado LGBTIQ+ y los legados que quedaban de su puesta en marcha o que podrían derivarse de su potencial implementación. Cabe señalar que todos los trabajos debían aparecer citados en bases de datos de revistas indexadas o circular en Google Académico y podían corresponderse con artículos de investigación, de revisión o de reflexión, o ser trabajos de grado aprobados de pregrado, posgrado o tesis doctorales.

La búsqueda arrojó pocas referencias en torno a los colectivos LGBTIQ+ (35), comparadas con lo recogido para PcD (143). Para los fines de este estudio, se seleccionaron 64 trabajos, 21 en el ámbito de las orientaciones sexuales e identidades de género diversas y 43 en el de la discapacidad. Como resultado de la revisión propuesta, pudimos determinar barreras y facilitadores diferenciados para ambos grupos de estudiantes en cuanto al ingreso a las instituciones, y aquellas que precisan para lograr su permanencia en estas, específicamente, lo que requieren, a día de hoy, para recibir una educación de calidad. A 
continuación, se expondrán los principales referentes teóricos que guiaron la investigación, la metodología empleada, los hallazgos más relevantes y sus implicaciones para la atención de esta población estudiantil en el sistema educativo colombiano, en el marco de la diversidad.

\section{Marco teórico}

Este trabajo se centró en el ámbito de la educación inclusiva, específicamente en lo que respecta a las barreras y los facilitadores que las PcD y los grupos LGBTIQ+ encuentran en su paso por la escolaridad. En ese orden de ideas, se adoptó la definición de educación inclusiva recogida a partir de los trabajos de Booth y Ainscow (2015), en cuya esencia se resalta la relevancia de identificar barreras y generar oportunidades para todo el estudiantado, más allá de sus particularidades y características:

La educación inclusiva es un enfoque que propone la eliminación de barreras, estigmas y métodos excluyentes para que todas y todos los estudiantes tengan oportunidades de ingreso, atención, permanencia, evolución y sostenibilidad dentro del sistema educativo y, posteriormente, proyección en la vida social, teniendo en cuenta sus necesidades específicas. (Duarte, Pabón, Ascencio y Gómez, 2019, p. 76)

De lo anterior se deriva que la educación inclusiva constituye un proceso que involucra a la totalidad de la comunidad educativa, exige un trabajo articulado con la familia y los diversos sectores de la sociedad y debe potenciar la diferencia y la diversidad (Echeíta, 2019). Asimismo, es aquella educación para todos y todas, en tanto tiene como uno de sus fines esenciales proveer a todo el estudiantado oportunidades de acceso y permanencia en el sistema educativo (Echeíta, 2019; Marulanda y García-Cepero, 2019; MEN, 2017a; UNESCO, 2019).

A tenor de estos argumentos, la educación inclusiva tiene como finalidad, entre otras, derribar todas aquellas barreras que impidan la plena presencia y participación del estudiantado en las comunidades educativas (Booth y Ainscow, 2015). Adicionalmente, debe procurar la generación de facilitadores que mejoren el aprendizaje y la convivencia entre todos los miembros del sistema educativo, maximizando así su bienestar y calidad de vida (Mella y cols., 2014). Cabe señalar que las barreras constituyen todas aquellas condiciones de los contextos que "impiden o inhiben a las personas el acceso y disfrute de oportunidades para su desarrollo" (Victoriano, 2017, p. 354). 
Desde la perspectiva de Cheshire (2019), las barreras comportan un conjunto amplio de obstáculos, entre los que podemos situar barreras actitudinales, derivadas de falsas creencias, barreras políticas e institucionales, barreras ligadas a la falta de conocimiento y formación, barreras físicas y arquitectónicas, entre otras. Por su parte, los facillitadores se definen como todos aquellos factores que posibilitan el ejercicio de procesos inclusivos exitosos (Victoriano, 2017). Se cuentan entre estos la disposición de recursos institucionales, redes de apoyo y políticas locales o nacionales que propendan por la generación de oportunidades educativas para todo el estudiantado (González y cols., 2019).

Diversas investigaciones coinciden en que una de las principales barreras que han afrontado las PcD en su paso por la escolaridad formal tiene que ver con las falsas creencias del profesorado sobre sus posibilidades de aprendizaje en las aulas regulares (Alemany y Villuendas, 2004; Avramadis, Bayliss y Burden, 2000; Britto, 2018). A pesar de que en América Latina diversas instituciones educativas permiten el ingreso de estudiantes con discapacidad, siguen manteniéndose prácticas de exclusión y marginación, por lo que no siempre se les involucra en los procesos de enseñanza que se implementan con sus pares (Ardanaz y cols., 2004) y el profesorado reporta bajas expectativas con respecto a sus progresos y rendimiento académico (Tárraga, Grau y Peirats, 2013).

Según lo reportado en estudios internacionales, los facilitadores para la inclusión educativa de este estudiantado han surgido de experiencias docentes implementadas por maestros y maestras, quienes se formaron en educación inclusiva y discapacidad. Este profesorado ha abierto las puertas de sus aulas a un ejercicio de inclusión que reconoce que, con los ajustes y flexibilixaciones pertinentes y adecuados, las PcD pueden aprender y desarrollarse, como cualquier otro individuo (Granada, Pomés y Sanhueza, 2013). De igual modo, otro facilitador lo constituye el trabajo decidido de las familias en pro de los derechos de esta población estudiantil, haciendo equipo con el profesorado y la comunidad escolar en general (González y Triana, 2018). El trabajo colaborativo entre docentes y el apoyo de las personas de dirección y personal administrativo a sus iniciativas constituye otro elemento que promueve la educación inclusiva de PcD (Ardanaz y cols., 2004).

Es importante señalar que, en Colombia, no se ubicaron trabajos específicos que documenten barreras y/o facilitadores para estos colectivos, en los distintos niveles de la educación básica y superior. Si bien se han sistematizado las percepciones y representaciones sociales del profesorado sobre la discapacidad y se han documentado estudios de caso que 
relatan experiencias de instituciones educativas concretas o de alumnos y alumnas particulares, no se tiene aún una mirada de conjunto.

En lo que corresponde al estudiantado LGBTIQ+ podemos decir que, en América Latina, desde principios de la década de 2010, las orientaciones sexuales y las identidades de género diversas han comenzado a comprenderse como expresiones de lo humano dejando atrás, poco a poco, el imaginario que las había convertido en enfermedades, frecuentemente asociadas a prácticas sexuales indeseadas (v.gr., el abuso sexual) y a otros fenómenos como el consumo de sustancias psicoactivas o el contagio por VIH-SIDA (Fast, 2016; Posada, 2019; Ramírez, 2018).

Con todo, una barrera que esta población debe afrontar en la escuela, según se ha reportado en trabajos provenientes de distintos países de América Latina, son las múltiples formas de violencia de las que son víctimas (Arango, 2017). Derivado de lo anterior, han surgido prácticas como la homolesbotransfobia (Rodríguez y Rivera, 2020) y continúan en aumento el bullying homofóbico y la idea de que la homosexualidad y el lesbianismo, por citar solo dos, constituyen pecados, son trastornos de la personalidad que deben tratarse (López, Martínez, Negrete y Paternina, 2016). Otra barrera que deben afrontar es el hecho de que la educación sexual que se ofrece en la escuela, aún no acoge esta diversidad y sigue penalizando las manifestaciones no binarias ni hegemónicas de la sexualidad (Ramírez, Torrado y Villegas, 2018). En ese sentido, las prácticas de convivencia de distintas escuelas de educación básica primaria y secundaria continúan privilegiando el desarrollo de una sexualidad binaria, en la que solo caben las identidades de género masculina y femenina y la orientación sexual heterosexual (Posada, 2019).

En lo que respecta a facilitadores para los colectivos LGBTIQ+, podemos afirmar que estos provienen, como en el caso de las $\mathrm{PcD}$, del trabajo conjunto familia-escuela. Este último se caracteriza por el reconocimiento de que las identidades de género y las orientaciones sexuales pueden transformarse a lo largo del ciclo vital, no necesariamente replican los modelos de las figuras cuidadoras y constituyen búsquedas y elecciones personales (Ceballos, 2014). Otro apoyo fundamental se sitúa en aquellas comunidades educativas que ya han trabajado por instalar culturas inclusivas y nuevas prácticas de relacionamiento social entre sus miembros. Esto permite que, en la convivencia diaria, se visibilicen valores como el respeto y el reconocimiento del otro, más allá de su identidad de género, su orientación sexual, su credo o sus creencias políticas. Uno de los objetivos formativos de dichas instituciones está 
en el cuidado del otro y en maximizar, además de competencias académicas, el bienestar personal y emocional de todo el estudiantado (Rivas y cols., 2014).

Con el ánimo de enriquecer el conocimiento sobre las barreras y facilitadores con que cuentan estas poblaciones en el sistema educativo colombiano, presentamos la metodología implementada y los resultados del presente estudio.

\section{Metodología}

\subsection{Enfoque investigativo}

Este trabajo se inscribe en las metodologías de investigación cualitativa y emplea, en particular, el análisis de contenido de fuentes secundarias, esto es, de datos y hallazgos recopilados u obtenidos por otros académicos en proyectos desarrollados de manera previa a esta revisión (Navarro y Díaz, 2007). Se empleó esta técnica, en virtud de sus bondades en relación con el objetivo que perseguía este proyecto:

(El análisis de contenido) permite recoger información con base en una lectura científica (metódica, sistemática, objetiva) de un texto escrito (...), para indagar sobre lo escondido, lo no aparente, lo no dicho por el mensaje y, por ende, comprender el verdadero significado de las comunicaciones de una manera crítica e intentando mantener la mayor objetividad posible (Ñaupas, Mejía, Novoa y Villagómez, 2014, pp. 391, 393).

La estrategia investigativa antes descrita se ha empleado en otros estudios de corte documental en el ámbito educativo (Navarro y Díaz, 2007), con el fin de establecer inferencias sobre materiales que no han sido abordados de forma sistemática, tal y como ocurre con aquellos considerados para este proyecto.

\subsection{Unidades de análisis}

Se tomaron 64 reportes de investigación, 28 de los cuales eran artículos científicos publicados en revistas indexadas, 16 trabajos de grado de pregrado y 20 de posgrado, todos avalados y en circulación en bases de datos de universidades y/o de material académico debidamente publicado (v.gr., Google Académico). Se descartaron artículos de divulgación o documentos de trabajo por no haber sido sometidos al proceso de evaluación por pares académicos. En todos los casos se leyó el título, el resumen y los referentes teóricos, además de realizar un análisis detallado de la metodología, los resultados y las conclusiones, con el fin 
de poder extraer la información necesaria de cara a establecer las barreras y facilitadores en el ingreso y permanencia a la educación para los colectivos considerados en esta investigación. La totalidad de los reportes incluidos fue seleccionada en el periodo comprendido entre enero de 2016 y noviembre de 2020. La fecha de la última búsqueda fue el 5 de este último mes. Para este primer trabajo, se ubicaron estudios solo en idioma español.

\subsection{Técnicas de recolección de la información}

Con el fin de recoger los artículos y trabajos que interesaban a esta investigación, se empleó la metodología de la declaración PRISMA (Urrútia y Bonfill, 2010), especialmente adaptada a estudios en ciencias sociales y educación (Álvaro-Mora y Serrano-Rosa, 2019). Según esta, son tres los pasos que exige la búsqueda y organización de los materiales que se emplean en revisiones documentales como la que subyace al presente estudio. En la fase de búsqueda inicial, se consultan las bases de datos y fuentes científicas en las cuales es posible ubicar investigaciones en torno al tema objeto de estudio y se recoge el número de publicaciones disponible. Para este caso, se realizó la consulta en el buscador integrado de los servicios de biblioteca de la Pontificia Universidad Javeriana, el cual permite ubicar documentos científicos en distintas bases de datos (v.gr., Scopus, Ebsco-Host, ProQuest, Science Direct, Web of Science, Pubmed, entre las más relevantes). De otro lado, se llevó a cabo una pesquisa en Google Académico, de cara a ubicar trabajos en los repositorios de las bibliotecas de universidades colombianas que aún no hubieran sido publicados en revistas indexadas.

Cabe señalar que la primera indagación se realizó introduciendo los términos "experiencias educativas", "discapacidad”, "orientaciones sexuales diversas", "identidades de género diversas", "grupos LGBTIQ+", "Colombia", empleando siempre los operadores booleanos AND, OR y NOT, de cara a obtener la mayor cantidad de registros posibles. Luego de eliminar publicaciones duplicadas, libros y revisiones teóricas generales en educación inclusiva se obtuvieron, en total, 285 publicaciones para estudios con colectivos LGBTIQ+ y 695 trabajos con discapacidad. Una vez filtrados aquellos registros anteriores a 2016, quedaron 35 trabajos con comunidades LGBTIQ+ y 143 con discapacidad. Dado que en estas primeras búsquedas se observó una escasa representatividad de investigaciones con estudiantes con Trastorno del Espectro Autista (en adelante, TEA), se realizó una nueva indagación intentando rastrear trabajos que contemplaran a este colectivo. Así las cosas, los términos empleados para esta consulta fueron "experiencias educativas", "Trastorno del 
Espectro Autista" y "Colombia”, usando los operadores booleanos mencionados previamente. Como resultado obtuvimos 27 trabajos centrados en autismo.

Atendiendo a la segunda fase de la metodología PRISMA, se realizó una búsqueda sistemática en los trabajos seleccionados en el momento anterior, con base en los criterios de inclusión y exclusión que se delimitaron para el proyecto, los cuales se exponen en la Tabla 1. Como producto de esta fase, quedaron 21 estudios con estudiantes LGBTIQ+ y 42 en discapacidad. Finalmente, en el tercer y último momento se realizó una búsqueda manual que permitió incorporar una tesis de maestría, cuyos resultados eran relevantes a los objetivos de este trabajo, no obstante, aún no aparecía en las bases de datos consultadas puesto que fue defendida y aprobada a inicios de noviembre de 2020.

Tabla 1

Criterios de inclusión y exclusión de los trabajos considerados para la presente investigación

\begin{tabular}{|c|c|c|}
\hline & Inclusión & Exclusión \\
\hline $\begin{array}{l}\text { Ámbito } \\
\text { temático }\end{array}$ & $\begin{array}{l}\text { Estudios en comunidades educativas } \\
\text { colombianas urbanas desarrollados en el } \\
\text { ámbito específico de la discapacidad o de los } \\
\text { colectivos LGBTIQ+, en los cuales se } \\
\text { señalaran barreras y/o facilitadores en el } \\
\text { ingreso o permanencia a la educación, con } \\
\text { relación a estos grupos (uno o ambos), como } \\
\text { parte de los objetivos, las conclusiones y/o } \\
\text { implicaciones de las investigaciones. Estas } \\
\text { podían ser en las siguientes áreas: } \\
\text { - Percepciones o creencias de agentes } \\
\text { educativos. } \\
\text { Sistematización de prácticas de aula } \\
\text { exitosas. } \\
\text { Propuestas novedosas y/o puestas en } \\
\text { marcha de programas o estrategias } \\
\text { pedagógicas para cualificar el } \\
\text { aprendizaje o mejorar la convivencia } \\
\text { escolar. } \\
\text { Estudios documentales en cuanto a la } \\
\text { implementación de políticas públicas } \\
\text { nacionales o locales. }\end{array}$ & $\begin{array}{l}\text { Revisiones teóricas de } \\
\text { materiales no referidos } \\
\text { a la situación educativa } \\
\text { en Colombia y/o sin } \\
\text { tomar en cuenta a } \\
\text { alguno de los dos } \\
\text { colectivos objeto de } \\
\text { este proyecto. } \\
\text { Análisis teóricos o } \\
\text { trabajos empíricos de } \\
\text { educación inclusiva en } \\
\text { general, con otros } \\
\text { colectivos distintos a } \\
\text { los que se focalizaron } \\
\text { en esta revisión o con } \\
\text { comunidades } \\
\text { educativas de otros } \\
\text { países distintos a } \\
\text { Colombia. } \\
\text { Estudios en salud o en } \\
\text { ámbitos que no } \\
\text { abordaran lo educativo. }\end{array}$ \\
\hline $\begin{array}{l}\text { Tipo } \\
\text { estudio }\end{array}$ & $\begin{array}{l}\text { Con enfoque cualitativo, cuantitativo o mixto } \\
\text { o estudios documentales relacionados con la } \\
\text { situación educativa de cualquiera de los dos } \\
\text { colectivos que interesaban a esta } \\
\text { investigación, desarrollados en Colombia. }\end{array}$ & $\begin{array}{l}\text { Estudios que no } \\
\text { involucraran el sistema } \\
\text { educativo y sus relaciones } \\
\text { con estudiantes objeto de } \\
\text { esta revisión (v.gr., estudios } \\
\text { de corte netamente } \\
\text { psicológico, terapéutico o } \\
\text { solo en el ámbito de la salud } \\
\text { o el derecho). }\end{array}$ \\
\hline
\end{tabular}

Los contenidos de este artículo están bajo una licencia Creative Commons 


\begin{tabular}{|c|c|c|}
\hline $\begin{array}{l}\text { Participantes } \\
\text { objeto de los } \\
\text { trabajos }\end{array}$ & $\begin{array}{l}\text { Estudiantes de educación inicial, básica } \\
\text { primaria, básica secundaria, media } \\
\text { vocacional o educación superior con } \\
\text { cualquier tipo de discapacidad y/o } \\
\text { pertenecientes a los colectivos } \\
\text { LGBTIQ+. } \\
\text { Maestros, maestras y agentes } \\
\text { educativos relacionados y/o } \\
\text { pertenecientes a cualquiera de los dos } \\
\text { colectivos que interesaban a este } \\
\text { trabajo. }\end{array}$ & $\begin{array}{l}\text { Estudiantes de otros } \\
\text { colectivos, PcD o de los } \\
\text { colectivos LGBTIQ+ que no } \\
\text { formaran parte de } \\
\text { comunidades educativas en } \\
\text { cualquier nivel educativo, } \\
\text { terapeutas o personal de la } \\
\text { salud. }\end{array}$ \\
\hline $\begin{array}{l}\text { Periodo } \\
\text { temporal }\end{array}$ & $\begin{array}{l}\text { ntre el } 1 \text { de enero de } 2016 \text { y el } 5 \text { de } \\
\text { oviembre } 2020\end{array}$ & a 2016 \\
\hline
\end{tabular}

Fuente: Elaboración propia, 2020

\subsection{Procesamiento de análisis de los textos recabados}

El análisis de contenido atiende a un conjunto de diversas fases todas las cuales se han seguido en este proyecto. A modo de síntesis, y siguiendo los presupuestos de Bardin (2002), se describirán los tres momentos claves de dicho proceso y cómo se llevaron a cabo en esta investigación: (a) pre-análisis; (b) examen del contenido; e (c) interpretación de los resultados. En el primer momento, y a la luz del objetivo que orientó el proyecto, esto es, caracterizar las barreras y facilitadores actuales de PCD y estudiantes LGBTIQ+, en cuanto a su ingreso y permanencia en el sistema educativo colombiano, específicamente en el contexto urbano, iniciamos recopilando y actualizando material teórico y empírico que nos indicara los ideales que debían cumplirse para una educación de calidad, oportuna y pertinente, dirigida especialmente a los dos grupos que interesaban a este trabajo. Para este ejercicio, seis documentos fueron esenciales:

1. La Declaración de Incheon promulgada por la UNESCO en 2015, desde cuya perspectiva la meta de la educación a nivel mundial para 2030 debe ser "garantizar una educación inclusiva, equitativa y de calidad y promover oportunidades de aprendizaje durante toda la vida para todos" (p. 1).

2. La Ley 1620 de 2013, gracias a la cual se crea el Sistema Nacional de Convivencia Escolar y Formación para el Ejercicio de los Derechos Humanos, la Educación para la Sexualidad y la Prevención y Mitigación de la Violencia Escolar (MEN, 2013).

3. El Decreto 762 de 2018 que da vida a la política pública para la garantía del ejercicio efectivo de los derechos de las personas de los sectores sociales LGBTIQ+ y de personas con orientaciones sexuales e identidades de género diversas (MEN, 2018).

4. La Convención sobre los Derechos de las Personas con Discapacidad y su Protocolo Facultativo, aprobados en 2006, en cuyo seno se defiende la necesidad del derecho a la 
educación (artículo 24), como un derecho humano fundamental del que no pueden escapar las PcD. Colombia la suscribe en mayo de 2011 (MEN, 2017a, p. 31).

5. El Decreto 1421 de 2017 en virtud del cual se reglamenta la atención educativa a la población con discapacidad, en el marco de la educación inclusiva (MEN, 2017b).

6. El documento de Orientaciones técnicas, administrativas y pedagógicas para la atención educativa a estudiantes con discapacidad en el marco de la educación inclusiva, expedido en 2017, y en el cual el MEN recoge las principales directrices de cara a hacer efectiva una educación de calidad para seis colectivos con discapacidad [v.gr., discapacidades sensoriales (ceguera, sordera, sordoceguera, entre otras), discapacidades físicas y dificultades de movilidad, discapacidad intelectual, Trastorno del Espectro Autista, discapacidades psicosociales y trastornos permanentes de voz y habla]. Este texto es de especial relevancia, pues allí se dictaminan los apoyos y algunos principios de intervención educativa que deben acogerse para todas y cada una de las $\mathrm{PcD}$ antes citadas ${ }^{3}$.

A la luz de la lectura y estudio de estos textos surgieron dos dimensiones relacionadas con el ingreso y permanencia de los dos colectivos en el sistema educativo colombiano. En cuanto al ingreso, la primera dimensión estuvo constituida por los imaginarios y creencias de distintos agentes educativos, en torno a los dos colectivos seleccionados, mientras que las políticas institucionales que regulan el acceso a la educación, se configuró como la segunda.

Las dimensiones seleccionadas para abordar la permanencia, a diferencia de las anteriores, se ubicaron de modo independiente para cada grupo de estudiantes, en función de sus particularidades y características. Así las cosas, para las $\mathrm{PCD}$ la primera dimensión tuvo que ver con las adaptaciones, ajustes y flexibilizaciones que se realizan en pro de cualificar su aprendizaje, reguladas y establecidas a nivel institucional, y la segunda con los recursos pedagógicos y de distinto tipo que ofrecieran las instituciones, de cara a ajustar las prácticas educativas y de aula a las oportunidades y requerimientos de esta población estudiantil, con el ánimo de superar todas aquellas barreras que habitualmente les impiden aprender con calidad. En cuanto a los colectivos LGBTIQ+, las dimensiones abordadas en la permanencia

\footnotetext{
${ }^{3}$ Una ventaja en la revisión de este documento es que la autora del presente artículo fue quien escribió dichos lineamientos como autora principal, con el apoyo en un equipo de expertos en discapacidad en Colombia y la asesoría de académicos internacionales. En ese orden de ideas, conoce de primera mano la situación global de los colectivos con discapacidad en este país, vigentes a 2017, muchas de cuyas características no han cambiado para 2020.
} 
estuvieron relacionadas, en primera instancia, con la generación de estrategias institucionales para promover culturas inclusivas que permitieran el libre ejercicio de la personalidad, en particular, el respeto y reconocimiento de la orientación sexual y la identidad de género, y en segundo lugar, los recursos de las entidades educativas para prevenir y mitigar el bullying y la violencia escolar, específicamente aquel dirigido al estudiantado de este colectivo.

La segunda fase del análisis de contenido se dedicó a elegir las unidades de registro y contexto de la investigación y a la categorización de la información. Así pues, las unidades de análisis fueron de carácter semántico y se vincularon con cada una de las seis dimensiones previamente señaladas (dos para el ingreso y cuatro para la permanencia, diferenciadas estas últimas por colectivo). Dada la naturaleza de este trabajo, aquellas unidades que no pudieron ubicarse en las dimensiones detalladas previamente se analizaron considerando su posible ubicación en otras nuevas. El resultado de este proceso se comentará en los hallazgos del estudio. Por su parte, las unidades de contexto estuvieron constituidas por los títulos, resúmenes, metodologías, marco teórico, resultados y conclusiones de los 64 trabajos elegidos y estudiados.

La fase final o de interpretación de las unidades de análisis previamente clasificadas no pudo escindirse completamente de las labores de categorización recogidas en el momento anterior. Así pues, estos dos pasos tomados en conjunto permitieron, por una parte, nutrir cada una de las dimensiones mencionadas más arriba haciendo acopio de los hallazgos de los diversos trabajos y, por otra, inferir, a partir de estos últimos, aquellas barreras y facilitadores de mayor relevancia en la actualidad para las PcD y LGBTIQ+ en Colombia.

\section{Resultados}

\subsection{Discapacidad y educación en Colombia: Una mirada de conjunto desde diversos niveles educativos}

En términos globales, la mayoría de trabajos consultados se corresponde con procesos de sistematización de experiencias de aula llevados a cabo en instituciones de educación básica primaria de carácter público, ubicadas en ciudades capitales (v.gr., Bogotá, Bucaramanga, Medellín y Cali). Un número importante de los estudios consideró como participantes el profesorado (22 de 43), así como estudiantes con discapacidades sensoriales (visual y/o auditiva) y/o discapacidad intelectual (30 de 43).

Gran parte de los trabajos se llevaron a cabo haciendo acopio de metodologías cualitativas, solo dos se definieron como investigaciones exploratorio-descriptivas de índole 
cuantitativa y corte transversal. La mayoría constituían estudios de caso de instituciones educativas (39\%) o de individuos o pequeños grupos (30\%). En este último escenario, los trabajos reportaron muestras que oscilaban entre uno y once participantes.

Cabe señalar que un $46 \%$ del total de estudios fue reportado como artículo de investigación, mientras que un $23 \%$ lo constituyeron trabajos de fin de grado y el $31 \%$ restante, trabajos de posgrado (Especialización y Maestría). Las figuras 1, 2, 3 y 4 ilustran datos descriptivos más detallados de los estudios analizados. En línea con las categorías de ingreso y permanencia consideradas para realizar el análisis de los trabajos, presentamos a continuación los resultados más relevantes para cada una y sus dimensiones, en los niveles de educación básica primaria, educación básica secundaria y media vocacional y, finalmente, en educación superior ${ }^{4}$.

Figura 1

Porcentaje de los trabajos revisados por tipos de estudio, Colombia, 2016-2020.

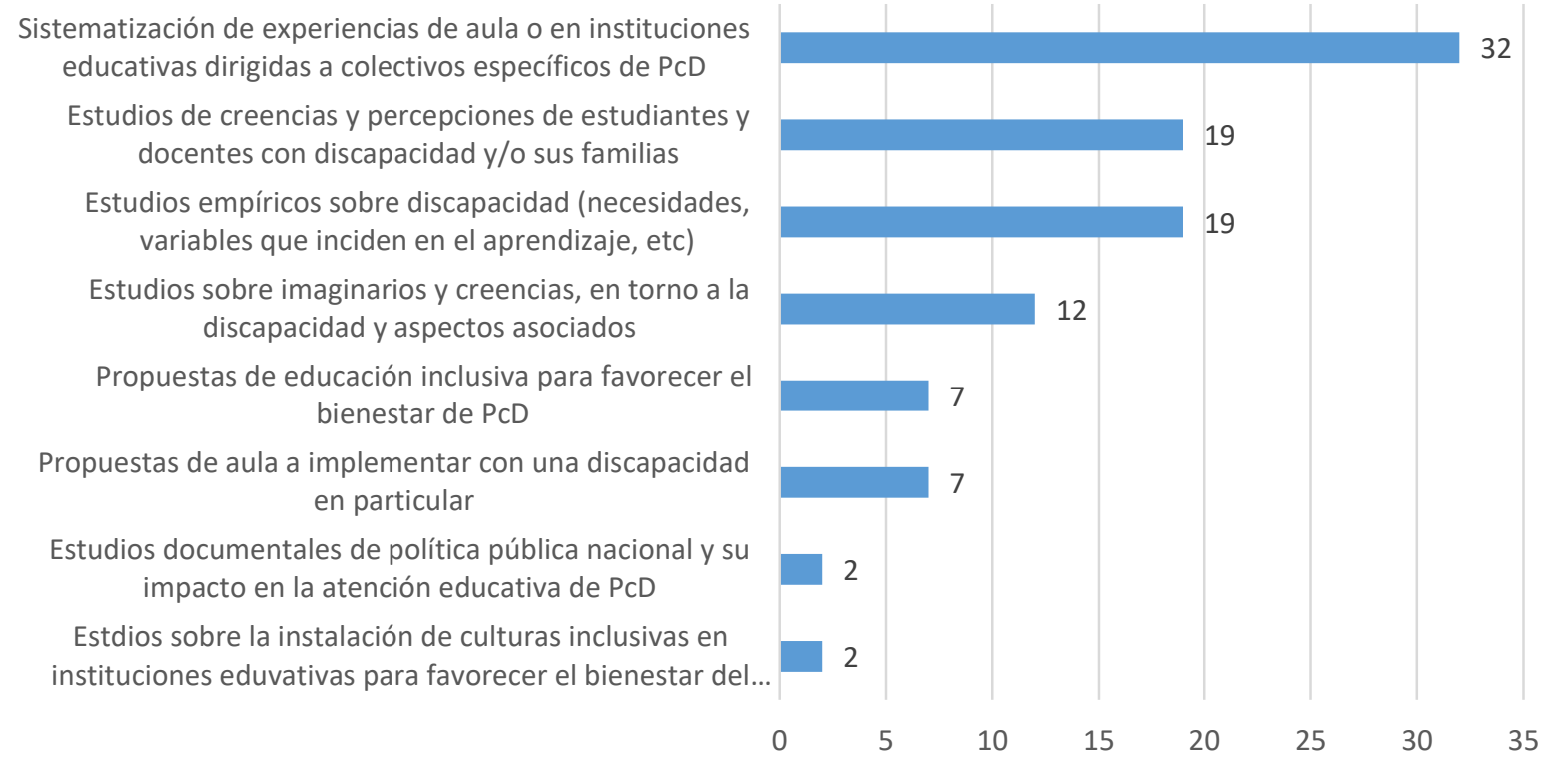

Fuente: Elaboración propia, 2020

\footnotetext{
${ }^{4}$ En Colombia, el sistema educativo está dividido en seis niveles educativos, así: (1) educación inicial que comprende los grados de prejardín hasta transición; (2) educación básica primaria que recoge desde primero hasta quinto grado; (3) educación secundaria que acopia los primeros cuatro grados del bachillerato; (4) educación media vocacional en la que se ubican los dos años finales del bachillerato; (5) educación técnica y tecnológica que recoge la formación en oficios y ocupaciones instrumentales para una rápida inserción laboral; y (6) educación superior o universitaria. Para los fines de este estudio, y dado que en educación inicial y técnica tecnológica apenas se ubicaron estudios, los resultados se presentarán atendiendo a las diferencias entre niveles educativos, organizados en tres grupos, a saber: (1) educación básica primaria; (2) educación básica secundaria y media vocacional; y (3) educación superior.
} 
Figura 2

Porcentaje de los colectivos con discapacidad incluidos en los estudios consultados, Colombia, 2016-2020.

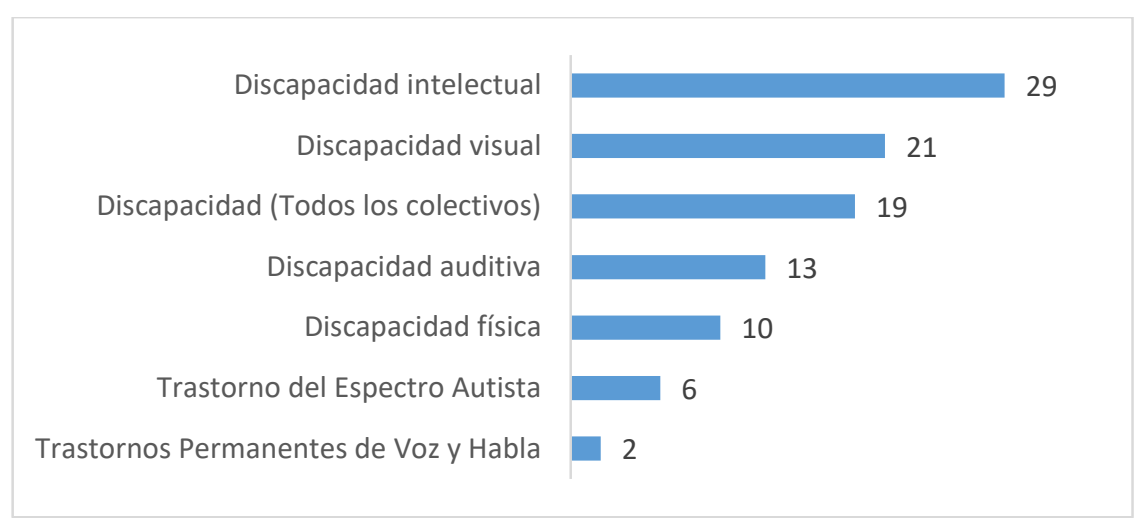

Fuente: Elaboración propia, 2020

Figura 3

Porcentaje de los participantes incluidos en los estudios revisados, Colombia, 2016-2020.

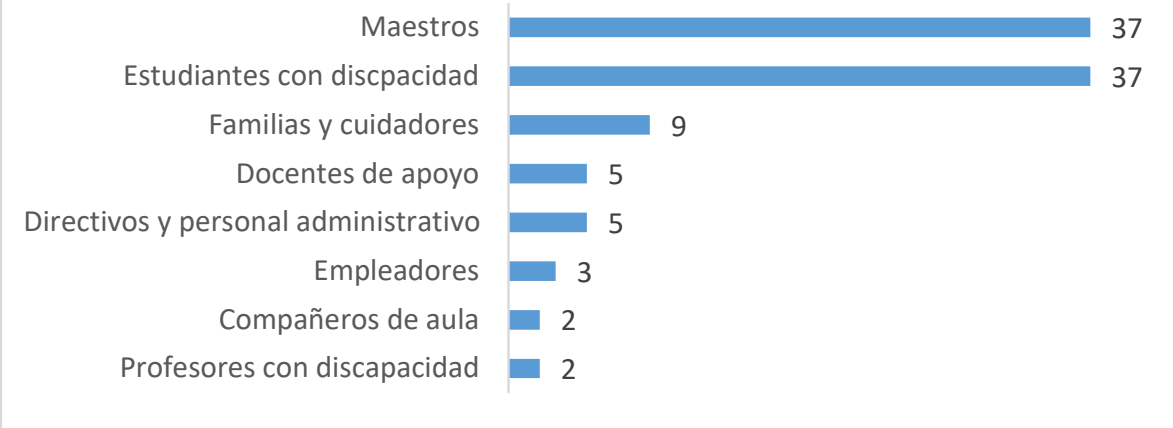

Fuente: Elaboración propia, 2020

Figura 4

Porcentaje de los trabajos en discapacidad y educación revisados para este estudio según niveles educativos, Colombia, 2016-2020.

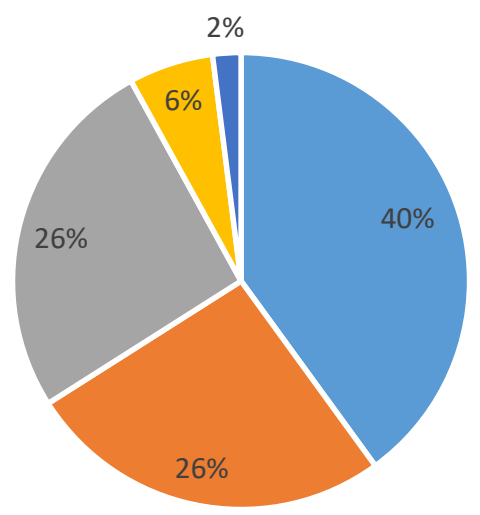

- Educación básica primaria
- Educación secundaria y
media vocacional
- Educación superior
- Educación inicial
- Educación técnica-
tecnológica

Fuente: Elaboración propia, 2020 


\subsubsection{Barreras y facilitadores en el ingreso al sistema educativo}

Con respecto al ingreso, observamos que un porcentaje de los trabajos consultados reporta una tendencia favorable de las comunidades educativas a aceptar el ingreso de PcD (19\%) (Álape, Barrero y Muñoz, 2018; Basto y Hernández, 2020; Castillo, 2019; Fernández y Duarte, 2016). En educación básica primaria encontramos que diversos colegios cuentan con lineamientos específicos al respecto de cómo proporcionar apoyos para el acceso de este colectivo a la educación (Acosta, Lugo y Solano, 2018; Cruz, 2019). Esto aplica, especialmente, para discapacidades sensoriales (Chaves, 2018), físicas (Acosta y cols., 2018) y, en algunos casos, para estudiantes con discapacidad intelectual y autismo (Morales y Borja, 2019).

En cuanto a la primera dimensión propuesta para el ingreso, referida a los imaginarios y creencias de la comunidad educativa, el profesorado de básica primaria refiere discursos basados en valores inclusivos y reconocen, en su mayoría, la necesidad de que las escuelas atiendan $\mathrm{PcD}$, en el marco del respeto y el reconocimiento por el otro (Basto y Hernández, 2020; Materón, 2016). Aunque todavía no se perciben como primeros responsables del aprendizaje de estudiantes con discapacidad, sus concepciones de niños y niñas con esta condición está cambiando (Castillo, 2019; Gutiérrez y Martínez, 2020). Derivado de esto último, el profesorado menciona que las $\mathrm{PcD}$ son sujetos con diversas habilidades y potencialidades que merecen el derecho a una educación con equidad (Castillo, 2019; Jácome, Pinilla y Rojas, 2019).

En cuanto a la dimensión de políticas institucionales para regular el acceso a la educación de estudiantes con discapacidad, encontramos que la gran mayoría de colegios privados en los niveles de educación básica primaria, así como diversos colegios públicos cuentan con normativas para garantizar el ingreso del estudiantado con discapacidad a sus aulas. En ese orden de ideas, se cuenta con equipos de psicorientación y psicopedagógicos que apoyan los procesos de admisión (Basto y Hernández, 2020), y se toman en cuenta las necesidades de las familias, de cara a cualificar los aprendizajes de esta población estudiantil en la escuela (Cabrera, Lizarazo y Medina, 2016).

En contraste con estos hallazgos, en educación básica secundaria y media vocacional encontramos imaginarios y creencias poco favorables en el profesorado, en torno a las PcD (Galeano, 2018; Gutiérrez y Martínez, 2020). Así las cosas, el cuerpo docente refiere todavía creencias como que el estudiantado con discapacidad debería asistir a instituciones especializadas para su formación (González y cols., 2019), y aunque perciben que podrían 
fortalecerse en habilidades sociales y emocionales si asisten a escuelas regulares, no consideran que cuenten con las habilidades suficientes para acceder a los contenidos académicos propios de este nivel educativo (Álape y cols., 2018; Basto y Hernández, 2020).

En lo que corresponde a la dimensión de políticas institucionales, se observa que, como en el nivel educativo anterior, la mayoría de instituciones privadas y públicas cuenta con normativas al respecto del ingreso de estudiantes con discapacidad; no obstante, estas no se transfieren a la práctica educativa cotidiana. En consecuencia, hay carencia de adaptaciones y flexibilizaciones en los exámenes y procesos de admisión (Díaz y Álvarez, 2016). Al parecer, los equipos de apoyo psicopedagógico de colegios privados concentran su foco de atención en el estudiantado con discapacidad de la básica primaria (Gutiérrez y Martínez, 2020), mientras que en los colegios públicos estos equipos trabajan con adolescentes y jóvenes con discapacidad si forman parte de las "aulas de apoyo" o "aulas inclusivas" (Ardila, Linares y Sierra, 2020). En estas, el estudiantado recibe apoyos específicos de tipo terapéutico y algunas ayudas para la realización de tareas escolares (Ardanaz y cols., 2004).

Finalmente, en educación superior los estudios consultados reportan que las PcD se han visto enfrentadas a prácticas de segregación y exclusión en los procesos de admisión. Estas últimas comportan la ausencia de adaptaciones a los instrumentos y pruebas que deben presentarse, acordes con las necesidades de aspirantes sordos, ciegos o con discapacidad intelectual, además de una visión de la PcD como limitada y deficitaria (Fresneda, 2019; Rodríguez, 2018). Los estudios abordados en cuanto imaginarios y creencias ratifican estas falsas creencias, especialmente en docentes (Gutiérrez y Martínez, 2020; Mejía, 2019; Romero y Urrego, 2016), aunque también en las personas directivas y personal administrativo (Fernández y Duarte, 2016; Galeano, 2018).

En cuanto a la dimensión de políticas institucionales, distintos trabajos reportan la existencia de lineamientos para el abordaje de procesos de admisión de PcD en algunas universidades tanto públicas como privadas de cuatro ciudades capitales del país (Mejía, 2019; Celemín y Flórez, 2018; Romero y Urrego, 2016). Tales lineamientos acogen estudiantes con discapacidades físicas o sensoriales, en particular, discapacidades visuales (Tenorio y Ramírez, 2016). Cabe señalar que colectivos con discapacidad intelectual y TEA no son contemplados dentro de estas orientaciones (Cruz, 2019; Díaz y Álvarez, 2016; Paredes, 2019).

A la luz del análisis global de los datos en los tres niveles educativos antes mencionados, surgió una nueva dimensión no contemplada previamente, que denominamos familia y acceso 
a la educación. Aunque pocos estudios del total revisado involucran padres, madres o cuidadores y sus relaciones con el entorno educativo formal (5 de 43), los trabajos analizados refieren escaso involucramiento de las familias en los procesos de admisión, especialmente en educación secundaria y superior.

Adicionalmente, reportan falta de sensibilidad a sus necesidades y requerimientos por parte de aquellos miembros de las comunidades educativas que lideran los procesos de admisión (Montaño, Cerón y Martín, 2019), y dificultades para construir canales de comunicación que posibiliten que la familia se constituya en un apoyo y así se pueda ofrecer equidad en los procesos de acceso a la educación para PcD (Acuña, Cabrera, Medina y Lizarazo, 2017). En particular, dos de los trabajos aluden a la necesidad de formar y sensibilizar a las personas cuidadoras para desmitificar en ellas falsas creencias sobre la discapacidad, dado que esta constituye una barrera que también impide que este estudiantado acceda a la educación formal, especialmente a la universidad (Acuña y cols., 2017; Arévalo, Cañón, Becerra, Mantilla, Guevara y cols., 2018).

\subsubsection{Barreras y facilitadores relacionados con la permanencia en el sistema educativo}

En lo que toca a la permanencia, encontramos un número importante de trabajos, cuya finalidad era sistematizar adaptaciones y flexibilizaciones (dimensión uno), de cara a generar oportunidades de aprendizaje para estudiantes con discapacidad. En el nivel de educación básica primaria, el $50 \%$ de los estudios revisados lo constituyen sistematizaciones de experiencias de aula basadas en adaptaciones curriculares de diverso tipo de contenidos para estudiantes con discapacidades visuales, discapacidad intelectual y TEA (Acero y Silva, 2019; Chaves, 2018; García y Martínez, 2019; Mayorga y Sánchez, 2018; Rodríguez, S.L., 2020). También encontramos programas de acompañamiento afectivo para niños y niñas con TEA (Chaves, Guerrero y Monroy, 2016; Rodríguez, S.L., 2020), así como la generación de recursos lúdicos para el aprendizaje de la matemática y la lecto-escritura, dirigidos a estudiantes con discapacidad intelectual (García y Martínez, 2019; Jácome y cols., 2019; Laiton, 2018).

En cuanto a la segunda dimensión, referida a la disponibilidad de recursos pedagógicos institucionales para el desarrollo de procesos de educación inclusiva, un 40\% de los estudios analizados en básica primaria reporta la existencia de recursos didácticos de distinto tipo al interior de las instituciones educativas. En todos estos casos, el profesorado cuenta con 
material lúdico de diversa clase, especialmente adaptado para poblaciones con discapacidades sensoriales, material documental para actualizar sus conocimientos en temas de inclusión y discapacidad y otros recursos para el trabajo con poblaciones con discapacidad intelectual (Acero y Silva, 2019; Mayorga y Sánchez, 2018).

Según los estudios analizados, un 60\% del profesorado de este nivel educativo ha recibido capacitaciones sobre educación inclusiva, específicamente relacionadas con la atención educativa a PcD. En virtud de esto último, los trabajos refieren mayor apertura del profesorado de educación básica primaria para la generación de flexibilizaciones y ajustes razonables dirigidos a colectivos con discapacidad. Un $70 \%$ de las investigaciones desarrolladas en este nivel educativo refiere que los docentes y el personal de apoyo de colegios públicos y privados emplea la herramienta de los Planes Individuales de Ajustes Razonables, a través de la cual se contemplan y acuerdan todos los apoyos que se proveerán al estudiantado con discapacidad para maximizar sus oportunidades de aprendizaje (MEN, 2017a).

En consonancia con los hallazgos anteriores, los trabajos abordados para educación básica secundaria y media vocacional también constatan algunas adaptaciones curriculares y experiencias de aula exitosas con estudiantes con discapacidad (Romero, 2019). Se observa un esfuerzo por desarrollar espacios para la transición a la educación técnica y tecnológica, y la vida laboral (Arévalo y cols., 2018), así como dinámicas de aula que propicien el desarrollo de habilidades científicas y sociales (Ardila, Linares y Sierra, 2020; Delgado y Moreno, 2018).

A pesar del éxito de estos esfuerzos, la gran mayoría de estas adaptaciones y ajustes termina quedándose en manos de docentes o estudiantes en formación que decidieron implementarlas, bien a título personal o como requisito para sus trabajos de grado o posgrado, pero no se acoge como política o lineamiento institucional. Un argumento que podría explicar este hallazgo, tiene que ver con las creencias e imaginarios sobre las PcD de docentes de la educación básica secundaria que ya se reseñaron previamente. Todavía sobreestiman la presencia de los apoyos terapéuticos y/o del profesorado de apoyo y los consideran como aquellas figuras que deben ocuparse de los procesos de flexibilización y adaptación curricular para PcD (Gutiérrez y Martínez, 2020), lo cual impide que se apropien y empoderen de esta labor como primeros responsables (Acosta y cols., 2018; Basto y Hernández, 2020; Chaves, 2018; Materón, 2016; Morales, 2018; Romero y Urrego, 2016).

Otra razón que podría explicar por qué las adaptaciones y flexibilizaciones son menos frecuentes en educación básica secundaria, en comparación con la básica primaria, tiene que 
ver con la carencia de procesos formativos para este profesorado que toquen y transformen sus prácticas educativas (Cruz, D.C., 2019; Madero, 2017; Parrado, 2020; Vesga, Pisso y Villaquirán, 2016). Es importante señalar que, en este nivel educativo, buena parte del profesorado que asume la tarea de generar por sí mismo los apoyos y ajustes para el aprendizaje de sus estudiantes con discapacidad, emplea los recursos por intuición, diseñándolos por su propia cuenta (Mayorga y Sánchez, 2018), dada la ausencia de capacitación (González y cols., 2019) o el poco respaldo con que cuenta por parte de las directivas de las instituciones educativas donde labora (Álape y cols., 2018).

Al hilo de lo anterior, en este nivel educativo, el profesorado refiere poca disponibilidad de recursos institucionales para el trabajo concreto con estudiantes con discapacidad (Cruz, D.C., 2019), la mayoría de los cuales se adquieren o diseñan especialmente para educación inicial o básica primaria. El profesorado también reporta escaso trabajo colaborativo con otros colegas en torno a estos temas, poco conocimiento del contexto y las dificultades específicas de sus estudiantes con discapacidad y ausencia de normativas institucionales que regulen los procesos de adaptación y flexibilización curricular (Basto y Hernández, 2020; Materón, 2016).

Durante los años de la educación media vocacional, los estudios revisados permiten concluir que, en pocos casos, se generan estrategias efectivas para la transición a la vida universitaria (Fresneda, 2019; Morales, 2018; y Rodríguez, 2018). Como corolario, las pruebas de Estado para ingresar a la educación superior tampoco toman en cuenta las necesidades y derechos de las PcD (Celemín y Flórez, 2018).

En lo que respecta a la educación superior, encontramos lo siguiente en cuanto a adaptaciones y flexibilizaciones. Las $\mathrm{PcD}$ que acceden a la vida universitaria perciben escaso apoyo del profesorado, especialmente si son PcD intelectual o con TEA. Las universidades que han abierto sus puertas al estudiantado con discapacidad se han centrado principalmente en las discapacidades sensoriales, dejando de lado otras condiciones (Molina, 2010). Aun así, en la gran mayoría de los casos, el estudiantado debe gestionar por el mismo los apoyos que requieren para formar parte de la comunidad educativa, especialmente si se trata de instituciones privadas (v.gr., intérpretes de lengua de señas). En esta misma línea, el estudiantado percibe barreras físicas y de infraestructura que no les permiten la libre movilización y acceso a los distintos lugares de las instituciones educativas, particularmente en los casos de discapacidad física y dificultades de movilidad (Linares, Hernández y Rojas, 2019; Zúñiga e Hincapié, 2021). 
En lo que corresponde a la dimensión de recursos pedagógicos, los estudios analizados indican que diversas instituciones de educación superior cuentan con recursos de diverso tipo para el trabajo con PcD, entre los que cabe destacar tecnología de punta y centros de recursos para el trabajo con discapacidades sensoriales y físicas. Las universidades privadas también reportan "programas de inclusión y diversidad" dirigidos a apoyar al cuerpo docente en la flexibilización de sus sistemas de enseñanza y evaluación, de modo que se ajusten a las necesidades del estudiantado con discapacidad (Morales, 2018; Parrado, 2020; Rodríguez, 2018). Aun así, el profesorado no emplea estos recursos sino esporádicamente y en diversos casos hay resistencias a flexibilizar las metodologías de aprendizaje o la evaluación (Cruz, M., 2019; Díaz y Álvarez, 2016; Mejía, 2019; Morales, 2018).

A modo de conclusión, podemos afirmar que los estudios recogidos y abordados en esta revisión evidencian avances en dos aspectos en particular. Por una parte, una mayor sensibilidad y conciencia por parte del profesorado de la educación básica primaria, referidos a la necesidad de generar oportunidades de acceso a la educación de las PcD. De otro lado, un conjunto de diversas adaptaciones y flexibilizaciones curriculares en la básica primaria y la secundaria que dejan ver ambientes de aprendizaje de calidad para alumnos y alumnas con distintos tipos de discapacidad. Asimismo, se observan sistemas de apoyo institucional, en particular, en la educación superior pública para la inclusión de estudiantes con discapacidades sensoriales (Tenorio y Ramírez, 2016). Las universidades privadas se están fortaleciendo en procesos de formación y acompañamiento al profesorado, en torno a la inclusión de alumnos y alumnas con discapacidad.

Con todo, la agenda de una educación inclusiva que acoja plenamente a las $\mathrm{PcD}$ en la educación formal debe derribar aún algunas barreras, con el fin de garantizar una educación que acoja a todo el estudiantado. En las instituciones de educación básica secundaria y educación superior se deben generar protocolos inclusivos en sus procesos de admisión, pensados para todas las personas, independientemente de sus particularidades. Es vital que se cuente con los recursos para realizar las adaptaciones pertinentes y oportunas a todos los instrumentos y pruebas a que haya lugar.

Adicionalmente, es fundamental continuar trabajando por derribar y transformar los imaginarios y creencias que tiene el profesorado de estos dos niveles educativos sobre la discapacidad. Sin duda alguna, estos constituyen una barrera que está frenando y dificultando la instalación de procesos inclusivos en diversas instituciones educativas del país. Al hilo de esta consideración, y en tercer término, es preciso seguir formando docentes en discapacidad, 
dirigiendo estos esfuerzos a la reconfiguración de sus prácticas de aula, más que a abultar conocimientos desvinculados de su saber y ejercicio profesional.

Finalmente, se hace necesario comprender que la educación inclusiva dirigida, en particular, a las PcD no se agota ni concluye en la adaptación de estrategias pedagógicas para el desarrollo cognitivo o la adquisición de contenidos disciplinares. Está atravesada, como en todos los casos, por procesos de configuración emocional, autodeterminación, desarrollo social e interpersonal, derivado de lo cual la educación colombiana también debe volcar sus esfuerzos en la cualificación de los espacios educativos formales para que se conviertan en escenarios de desarrollo socio-emocional para las PcD (Parrado, 2020; Rodríguez, S.L., 2020).

\subsection{Orientaciones sexuales e identidades de género diversas y el contexto educativo: Barreras y facilitadores en las comunidades colombianas}

Tradicionalmente, la escuela se ha definido como un espacio para el desarrollo libre de la personalidad, cuya tarea no se restringe en exclusividad al enriquecimiento de habilidades cognitivas o a la adquisición de conocimientos científicos, sino que también comporta el despliegue de destrezas sociales, emocionales, políticas y morales que le permitan a los individuos constituirse integralmente en el seno de la sociedad (Ramírez, 2018; UNESCO, 2015). A pesar de que este llamado se consigna en numerosos documentos de la política educativa colombiana a nivel nacional, las escuelas en este país siguen siendo escenarios para la formación académica, fundamentalmente. La gran mayoría deja pasar las prácticas de violencia y bullying, y no despliega acciones de reparación ni preventivas, sino solo punitivas (Posada, 2019). De ello se derivan los resultados, no menos que alarmantes, producto de la Encuesta de Clima Escolar y Victimización realizada en 2013 por la Secretaría de Educación de Bogotá (SED), en la que 581 jóvenes, estudiantes de colegios públicos de la capital, denuncian, de manera anónima, diversas formas de violencia derivada de su orientación sexual o identidad de género, proveniente de distintos agentes educativos, no solo de pares o compañeros de clase:

Un 67\% de los estudiantes LGBTIQ+ se siente inseguro en el entorno escolar debido a su orientación sexual o identidad de género (...) y muchos sufren silenciosamente este tipo de violencia, pues en las propias instituciones son sancionadas las orientaciones sexuales diversas. (Ramírez, 2018, pp. 87-88) 
A nivel de país, se carece de datos que confirmen o desmientan lo anterior. Aun así y ante la falta de información al respecto, resulta vital preguntarse por las barreras y facilitadores que han atravesado a este colectivo en Colombia, derivados de su lucha por una educación inclusiva. Esta búsqueda nos recuerda la importancia de que la escuela se convierta en territorio de transformación social, en cuyo seno se promuevan el respeto y el reconocimiento de la diversidad (UNESCO, 2019). En este orden de ideas, nuestra revisión deja ver que la mayoría de estudios se centra en el ámbito de la educación superior, con apenas indagaciones en educación básica secundaria, solo un trabajo en educación inicial y ninguno en básica primaria. Por esta razón, abordaremos las barreras y facilitadores para el ingreso y la permanencia centrándonos en la educación superior, pues no hay datos disponibles para concluir sobre otros niveles educativos.

La totalidad de los estudios tiene como objeto abordar el efecto de las creencias e imaginarios sobre los colectivos LGBTIQ+ en los procesos de ingreso y permanencia de esta población estudiantil en las instituciones educativas. Únicamente uno de los 21 documentos presenta una propuesta para erradicar el matoneo hacia este colectivo. Ocho de los veintiuno son artículos de investigación, seis son trabajos de grado, seis de posgrado y uno es una tesis doctoral. Los datos sobre qué investigaciones emplearon personas y cuáles documentos, así como algunos detalles de los participantes de los estudios se ilustran en las Figuras 5 y 6 , respectivamente.

En términos generales, son frecuentes los estudios de caso con estudiantes transgénero y sus percepciones sobre imaginarios, creencias y barreras que les han permitido o no una plena educación en el escenario universitario, en particular si se encuentran en el periodo de tránsito o deciden iniciarlo mientras cursan sus estudios de pregrado. En un segundo lugar, se sitúan los trabajos que abordan actitudes y representaciones sociales sobre estos colectivos por parte de las comunidades heterosexuales, y qué prácticas de exclusión y marginación observan estos en sus centros educativos que afectan el bienestar de las personas LGBTIQ+. 
Figura 5

Porcentaje de los estudios revisados según tipo de los grupos de participantes, Colombia, 2016-2020.

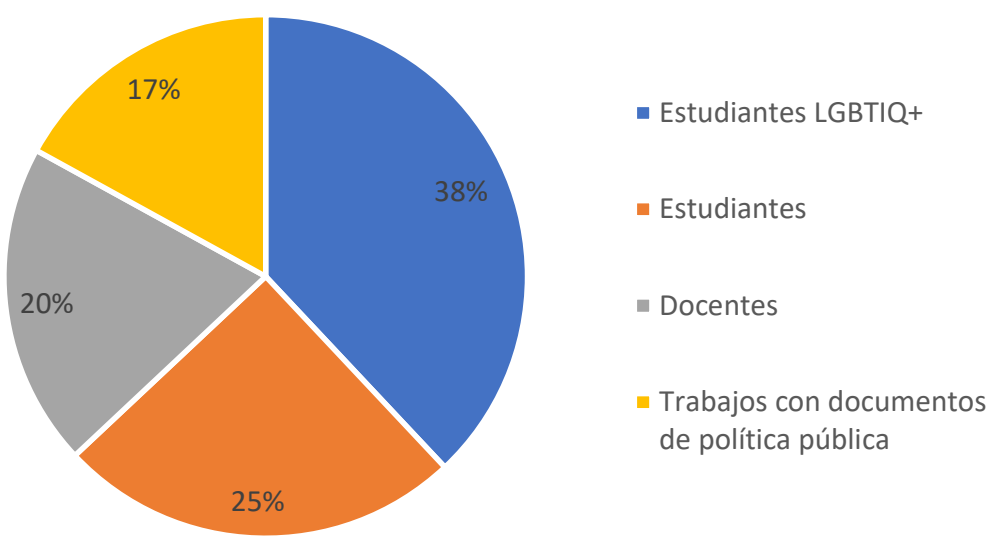

Fuente: Elaboración propia, 2020

Figura 6

Porcentaje del total de participantes con orientaciones sexuales o identidades de género diversas que participaron como sujetos de investigación en los estudios revisados

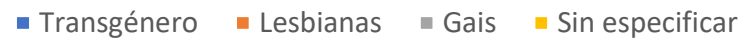

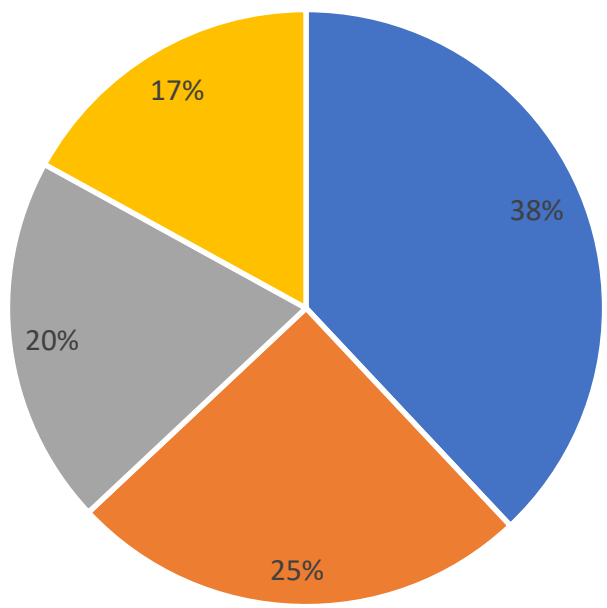

Fuente: Elaboración propia, 2020 


\subsubsection{Barreras y facilitadores en el ingreso a la educación}

En lo que toca a imaginarios y creencias (dimensión 1), abundan aún miradas patologizantes y denigrantes de las orientaciones sexuales o identidades de género no hegemónicas, lo que ha conllevado, en especial, a prácticas de acoso verbal para con estos colectivos, a través de términos peyorativos (v.gr., mariquita, maricón, niñita, marimacho, etc.), muchas de las cuales se han normalizado en la escuela (Posada, 2019; Quiceno y Mora, 2016; Ramírez, 2018; Zambrano, Hernández y Guerrero, 2019). Esto último da cuenta de que este aspecto de la diversidad no se percibe como parte de hacerse humano, sino como una enfermedad o desviación con respecto a lo mal llamado "normal" (Posada, 2019).

El conjunto de falsas creencias que aún perviven en torno a los grupos LGBTIQ+ como, por ejemplo, que constituyen trastornos psiquiátricos que deben tratarse, que provocarán prácticas sexuales irresponsables asociadas al contagio de VIH y otras enfermedades de transmisión sexual, entre otras, trae como consecuencia el debilitamiento de las redes de apoyo y una tendencia al ocultamiento e invisibilización de la diferencia (Acero, Galeano y Meza, 2018; Barreto, 2019; Barreto y Villalobos, 2019; López y cols., 2016). Estos imaginarios parecen aún extendidos entre maestros, maestras y familiares, especialmente padres y hermanos varones, según lo refieren los participantes de los grupos LGBTIQ+ que formaron parte de algunos de los estudios (Arango, 2017; Espinosa, 2019; Guzmán, 2016).

En lo que respecta a políticas de admisión, ninguna de las instituciones de educación superior considerada en las investigaciones revisadas, cuenta con normativas establecidas y/o de conocimiento general. El estudiantado transgénero, en particular, perciben barreras de acceso cuando no cuentan aún con un documento de identidad que refleje el género al que transitan o con el que realmente se identifican. Otros grupos LGBTIQ+ ocultan su identidad de género o su orientación sexual por temor a represalias y exclusiones. De modo sorprendente, no se encontraron registros de cifras de ingreso, permanencia o egreso de estos colectivos a ninguno de los niveles educativos del sistema de educación colombiano.

En lo que se refiere a los procesos de ingreso a las instituciones educativas, varios de los estudios reportan cómo todas estas creencias terminan convirtiéndose en razones implícitas para excluirlos de las posibilidades de acceso a la educación, si develan su identidad de género o su orientación sexual (Polo, 2018; Ramírez, 2018). Tales prácticas han derivado en múltiples acciones de tutela por parte de las familias y el estudiantado LGBTIQ+, en virtud de las cuales han emergido sendas sentencias de la Corte Constitucional Colombiana exigiendo derribar "actitudes de rechazo encubierto" que niegan la equidad de oportunidades 
y van en contra de lo que se considera una educación inclusiva (v.gr., sentencias 562 de 2013, 804 de 2014 y 478 de 2015) (Para una revisión exhaustiva, véase Ramírez, 2017). Cabe señalar que, para esta categoría en concreto, no se encontraron facilitadores.

\subsubsection{Barreras y facilitadores vinculados con la permanencia en el sistema educativo}

Al abordar la categoría de la permanencia del estudiantado LGBTIQ+ en un sistema educativo que privilegie su bienestar y calidad de vida, el panorama es altamente preocupante. Analizando la instalación de culturas inclusivas, un porcentaje importante de los trabajos (81\%) refiere la presencia de fenómenos como la homofobia, la lesbofobia, la transfobia y otras prácticas de segregación para con las personas LGBTIQ+ (Arango, 2017; Guzmán, 2016; Pinilla, 2017; Sanjuanelo, Jiménez, Rodas, 2016). La mitad de los trabajos realizados con participantes de estos colectivos reporta la presencia de trastornos emocionales e intentos de suicidio producto del bullying homofóbico y las prácticas de violencia a las que son sometidos y que cubren un amplio espectro de agresiones (v.gr., maltrato verbal, agresiones físicas, ciberbullying) (Acero y cols., 2018; Arango, 2017; Barreto, 2019; Espinosa, 2019; Quiceno y Mora, 2016).

Si bien en algunas instituciones de educación superior se han dado avances importantes y ya se están instalando espacios de reconocimiento de la diversidad sexual y de género (Polo, 2018), lo que caracteriza a estos escenarios aún no permea la cultura educativa de las comunidades en su totalidad. Así, por ejemplo, parte del estudiantado transgénero que inician su proceso de tránsito en la universidad refieren cómo el profesorado se niega a llamarlos por sus nuevos nombres y les siguen reconociendo como personas del género que abandonan, lo cual ocasiona estigmatizaciones y rechazos por parte de los grupos de pares y del personal administrativo de sus universidades (Acero y cols., 2018; Arango, 2017; Guzmán, 2016).

Algunos de los trabajos también confirman que los hombres heterosexuales son menos tolerantes a la expresión de orientaciones sexuales e identidades de género diversas, comparados con mujeres heterosexuales (Ballén y Moreno, 2020; Campo, Herazo y Oviedo, 2017). Asimismo, los estudios constatan que la identidad de género de menor aceptación se ubica en las personas transgénero, especialmente en los hombres que hacen su paso a la identidad de género femenina (Arango, 2017; Rodríguez y Rivera, 2020). Otros trabajos corroboran que la edad y la orientación religiosa son dos factores íntimamente asociados con prácticas de exclusión de colectivos LGBTIQ+. Así las cosas, a mayor edad y una prolongada adherencia a prácticas religiosas hegemónicas, menor tolerancia y apertura a las necesidades 
de reconocimiento de la diversidad (Barreto y Villalobos, 2019; López y cols., 2016). Todos estos elementos contribuyen a perpetuar culturas de marginación y exclusión de aquellas sexualidades e identidades de género no binarias.

En cuanto a la prevención y mitigación de prácticas de violencia en contra de los grupos $L G B T I Q+$ (dimensión 2 de la categoría de permanencia), encontramos que las instituciones no tienen protocolos de actuación al respecto, e invisibilizan o minimizan los sucesos que ocurren al respecto, según relatan las propias personas pertenecientes a estas comunidades (Sanjuanelo, Jiménez y Rodas, 2016; Zambrano y cols., 2019). En algunas ocasiones, se culpa a la persona cuya identidad de género u orientación sexual es diversa, afirmando que "provoca" las agresiones y que sus conductas son "desviadas o impropias" (Posada, 2019; Ramírez, 2018; Sentencia T-478 de 2015). Esto deja un escaso margen de acción que no permite prácticas de reparación y cierra la puerta a cualquier aprendizaje sobre el reconocimiento del otro y la diferencia en la escuela.

La gran mayoría del estudiantado universitario incluido en los trabajos revisados afirma que una temprana y adecuada educación sexual que permita la construcción de la identidad de género bajo los principios del respeto y la libertad de expresión, es la clave para empezar a generar cambios en el sistema educativo hacia una comprensión plena de la diversidad (Ramírez y cols., 2018; Pinilla, 2017). Educar en la sexualidad no puede seguir siendo sinónimo de prevención de embarazos adolescentes, y debe iniciar en los primeros años de la escolaridad (Ramírez y cols., 2018; Ramírez y Cardona, 2020). Asimismo, es esencial el apoyo institucional a aquellos grupos que agremian a estos colectivos y reivindican sus derechos (Polo, 2018) y la generación de espacios de sensibilización a las comunidades educativas que les permitan comprender cómo se constituye y configura la identidad de género y la orientación sexual, más allá de los prejuicios, censuras e imaginarios que circulan a diario, sin ninguna base científica (Acero y cols., 2018; Espinosa, 2019; Rodríguez y Rivera, 2020; Rodríguez, V.A., 2020).

Tomados en conjunto, los distintos estudios confirman que aún queda un largo camino por recorrer en el sueño de una educación que atienda con calidad la diversidad sexual que es propia de nuestra condición como humanos. Las instituciones educativas deben generar lineamientos y protocolos para cuidar el ingreso y acceso de la población estudiantil LGBTIQ+ a la educación, así como trabajar arduamente por desmontar estereotipos y falsas creencias y sensibilizar a las comunidades educativas en torno al respeto y reconocimiento de la diferencia. Finalmente, aunque no menos relevante, es fundamental promover espacios de 
prevención, cuidado del otro y visibilización de lo diverso, para lo cual se precisa de la generación de programas de educación sexual temprana y la instalación de culturas inclusivas que transformen los modos de relacionamiento y vinculación con el otro.

\section{Conclusiones, alcances y limitaciones del estudio}

El objetivo de este trabajo se centró en identificar las barreras y facilitadores que caracterizan el ingreso y permanencia de estudiantes con discapacidad y estudiantes LGBTIQ+ en el sistema educativo colombiano. Si bien son distintos y variopintos los frentes que deben atenderse, tal y como ha quedado plasmado en los resultados del estudio, podemos destacar tres retos en torno a los cuales se debe seguir trabajando de manera prioritaria. El primero tiene que ver con la sensibilización y desmitificación de falsas creencias en las comunidades educativas. Se hace esencial que ambos colectivos sean visibles y no estigmatizados en las instituciones educativas, para lo cual es fundamental preparar a todos los miembros de las escuelas para que los acojan en su diversidad, como también abrir espacios que permitan dialogar sobre las diferencias y poner sobre la mesa los mitos, imaginarios y prejuicios que abundan en torno a este estudiantado, para así generar caminos que permitan desterrar estas ideas, resignificarlas e instalar otras nuevas.

En segunda instancia, es fundamental generar protocolos, lineamientos y orientaciones con el profesorado, el alumnado y las comunidades educativas en pleno, que ayuden a trazar rutas para que el acceso y la permanencia de todo el estudiantado estén libres de barreras y se reconozcan los dispositivos para detectar estas últimas y convertirlas en oportunidades. Por último, se hace indispensable formar al profesorado y dotarlo de recursos que le permitan transformar sus prácticas pedagógicas, de modo que poco a poco incorporen la diversidad como un eje transversal de su ejercicio profesional.

Todos estos hallazgos plantean derroteros interesantes para la transformación y el fortalecimiento de las prácticas pedagógicas de docentes, en particular en la educación secundaria y superior en Colombia. Nuestro estudio es congruente con otros realizados al respecto en PcD (González y cols., 2019; Mella y cols., 2014; Victoriano, 2017) y en colectivos LGBTIQ+ (Fast, 2016). Erradicar las barreras que aquí hemos puntualizado resultará fundamental para construir el camino hacia una educación de buena calidad para todo el alumnado. Esta meta requerirá de la conformación de redes de trabajo conjunto entre docentes de distintos niveles educativos, a través de las cuales sea posible identificar las falsas creencias que están a la base de las resistencias del profesorado a trabajar con PcD o 
estudiantes LGBTIQ+, las emociones que ello les genera y cómo resignificarlas. Aquí será fundamental incorporar lo que hoy sabemos sobre cada uno de estos colectivos y sus posibilidades en la escuela y más allá de esta.

Un asunto crucial será la posibilidad de crear espacios para compartir y sistematizar las experiencias de aula y las adaptaciones curriculares exitosas, de modo que puedan replicarse y emplearse en diversos colegios y centros educativos. En la formación de licenciados y licenciadas también tendrá que darse una mirada profunda y estructural a los planes de estudio para dotar a quienes serán docentes en el futuro de suficientes herramientas de cara a su trabajo con la diversidad, que debería ser la norma, no la excepción (Echeíta, 2019).

Si este camino comienza a trazarse desde ya, el reconocimiento del otro y la visibilización de nuestras diferencias como oportunidades de desarrollo, se constituirá en el nuevo paradigma que caracterice a los sistemas educativos, tal y como está ocurriendo en la educación básica primaria en Colombia y en otras latitudes. Solo así, las PcD y la población estudiantil LGBTIQ+ encontrarán el lugar que merecen en la escuela, en tanto sujetos de derechos, para no ser marginados, segregados ni excluidos y seguirá tejiéndose esa «escuela ordinaria inclusiva» que no necesitará este último adjetivo para identificarse como tal (Slee, 2012).

En cuanto a futuros estudios que tomen como insumo lo construido en este, será conveniente recoger trabajos en una ventana de tiempo más amplia y expandiendo la búsqueda por niveles educativos y otros actores del sistema educativo. También debería pensarse en un abordaje empírico que indagara por las barreras y facilitadores desde las voces del propio estudiantado, sus docentes y familias, usando narrativas o enfoques cualitativos y/o cuantitativos de investigación.

\section{Referencias}

Acero, Angélica María., Galeano, Carlos Eduardo., y Meza, Keyla. (2018). "No estamos enfermos": Experiencia de un hombre trans durante el proceso de transición (Trabajo de grado no publicado). Fundación Universitaria Católica Lumen Gentium, Cali, Colombia.

Acero, Sandra Milena., y Silva, Enith. (2019). Estudio de caso. Una mirada para el aprendizaje en el aula con una niña con discapacidad intelectual en la institución educativa Marruecos y Molinos, Bogotá, D.C. (Tesis de Especialización no publicada). Universidad Cooperativa de Colombia, Bogotá, Colombia.

Acosta, Lina Alejandra., Lugo, Jhina Marcela., y Solano, Fanor Julián. (2018). Educación inclusiva en las instituciones educativas de Caicedonia - Valle del Cauca, Colombia. Perspectiva. Revista de Trabajo Social e Intervención Social, (25), 113-140. 
Acuña, Lina María., Cabrera, Victoria Eugenia., Medina, Diana Carolina., y Lizarazo, Flor Alba. (2017). Necesidades de la familia y la escuela en la educación de niños con discapacidad intelectual. Revista de Investigaciones, 9(1), 126-137.

Álape, Luz Ángela., Barrero, Leidy Viviana., y Muñoz, Diana Fernanda. (2018). Caracterización de creencias y conocimientos de maestros del sistema educativo de Bogotá en torno a la discapacidad intelectual leve. Un abordaje desde los principios de la educación inclusiva (Trabajo de Maestría no publicado). Pontificia Universidad Javeriana, Bogotá, Colombia.

Alemany, Inmaculada., y Villuendas, María Dolores. (2004). Las actitudes del profesorado hacia el alumnado con necesidades educativas especiales. Convergencia. Revista de Ciencias Sociales, 11(34), 183-215.

Álvaro-Mora, Cristina., y Serrano-Rosa, Miguel Ángel. (2019). Influencia de la formación musical en el rendimiento académico. Una revisión bibliográfica. Anuario de Psicología, 49(1), 18-31.

Arango, Mauricio Alexander. (2017). Prácticas de exclusión social y construcción identitaria de personas transgénero en contextos universitarios (Trabajo de Maestría no publicado). Universidad de Antioquia. Medellín, Colombia.

Ardanaz, Leonor., Armejach, Rita., Asensio, Cecilia., Bascón, Rafael., Bellés, Rosa., Del Carmen, Luis., ... Tudela, Jordi. (2004). La escuela inclusiva. Prácticas y reflexiones. Barcelona: Graó.

Ardila, Olga Lucía., Linares, Leidy., y Sierra, Cristian. (2020). Redes y alianzas para el fortalecimiento de los modelos de ensñeanza dirigidos a la población con discapacidad intelectual de las instituciones de formación aliadas a Best Buddies-Colombia (Trabajo de grado no publicado). Corporación Universitaria Minuto de Dios, Bogotá, Colombia.

Arévalo, Stehefany; Cañón, Luisa Fernanda; Becerra, Ana María; Mantilla, Luisa Fernanda, Guevara, Daira Fernanda y cols. (2018). El currículo como base del proyecto de vida de jóvenes con discapacidad intelectual. Una experiencia desde el colegio Juan Francisco Berbeo, IED (Trabajo de grado no publicado). Universidad Pedagógica Nacional, Bogotá, Colombia.

Artiles, Alfredo., Kozleski, Elizabeth., y Waitoller, Federico. (2011). Inclusive education. Examining equity on five continents. Harvard: Harvard University Press.

Avramidis, Elías., Bayliss, Phil., y Burden, Robert. (2000). A survey into mainstream teachers' attitudes towards the inclusion of children with special educational needs in the ordinary school in one local education authority. Educational Psychology, 20(2), 191-211.

Ballén, Brenda., y Moreno, Daniela Rocío. (2020). Influencia del género en la aceptación de la homosexualidad en estudiantes de ingeniería civil de la Universidad Cooperativa de Colombia - Campus Villavicencio (Trabajo de grado no publicado). Universidad Cooperativa de Colombia, Villavicencio, Colombia. 
Bardin, Laurence. (2002). Análisis de contenido. Madrid: Akal.

Barreto, Bibiana Lucía. (2019). Experiencia de la orientación sexual diversa y la identidad de género en la universidad como escenario de formación y desempeño laboral: Dos historia de vida en la Universidad de Ibagué (Trabajo de Maestría no publicado). Uniandes, Bogotá, Colombia.

Barreto, Julián Andrés., y Villalobos, Víctor Alfonso. (2019). Representaciones sociales de la inclusión de la población LGBTI en la educación superior en la Facultad de Salud de la Universidad del Bosque (Trabajo de Especialización no publicado). Universidad del Bosque, Bogotá, Colombia.

Basto, Carolina., y Hernández, María Isabel. (2020). Creencias sobre discapacidad de un conjunto de maestros de educación básica primaria, básica secundaria y media vocacional de la ciudad de Bogotá, D.C. (Tesis de Maestría no publicada). Pontificia Universidad Javeriana, Bogotá, Colombia.

Booth, Tony., y Ainscow, Meil. (2015). Guía para la educación inclusiva. Desarrollando el aprendizaje y la participación ciudadana en los centros escolares. Madrid: OEI.

Britto, Katherine. (2018). Concepciones y creencias sobre la educación inclusiva de estudiantes universitarios de la carrera de educación primaria (Teis de Licenciatura en Psicología Educacional). Pontificia Universidad Católica del Perú, Lima, Perú.

Cabrera, Victoria Eugenia., Lizarazo, Flor Alba., y Medina, Diana Carolina. (2016). Necesidades de relaciones sociales de niños y niñas con discapacidad intelectual en la familia y en la escuela. Revista Educación y Desarrollo Social, 10(2), 86-101.

Campo, Adalberto., Herazo, Edwin., y Oviedo, Heidi Celina. (2017). Correlación entre actitud hacia homosexualidad femenina y masculina en estudiantes de medicina. Psicogente, 20(37), 172-180.

Castillo, Jennifer. (2019). Imaginario de licenciados en formación de Pedagogía Infantil frente a la educación inclusiva de estudiantes con discapacidad (Trabajo de grado no publicado). Fundación Universitaria Los Libertadores, Bogotá, Colombia.

Ceballos, Marta. (2014). Identidad homosexual y contexto familiar heteroparental: Implicaciones educativas para la subversión social. Revista Latinoamericana de Ciencias Sociales, Niñez y Juventud, 12(2), 643-658.

Celemín, Juan Camilo., y Flórez, Rita. (2018). Percepción sobre factores que inciden en los resultados de las pruebas SABER 11 de la población sorda. Una mirada desde tres instituciones educativas de Bogotá, D.C., Colombia. Revista de la Facultad de Medicina, 66(3), 349-356.

Corte Constitucional de Colombia. (2015). Sentencia T-478-15. Bogotá: Autor. 
Cruz, Diana Carolina. (2019). Parámetros útiles para la clasificación de instituciones educativas según sus condiciones de inclusión. Estudio de cinco casos en el Huila, Colombia. Revista PACA, (9), 111-127.

Cruz, Melissa Stefanía. (2019). Lineamientos de educación inclusiva para estudiantes con discapacidad en la educación superior colombiana. Revista Latinoamericana en Discapacidad, Sociedad y Derechos Humanos, 3(1), 50-69.

Chaves, Paula Yicel. (2018). Diseño de un programa piloto de formación a maestros para la educación inclusiva de población con discapacidad visual: Una experiencia desde la perspectiva fonoaudiológica (Trabajo de grado no publicado). Universidad del Rosario, Bogotá, Colombia.

Chaves, Diana Marcela., Guerrero, Karen., y Monroy, Cindy Paola. (2016). Ambientes de aprendizaje: Aportes a los procesos socio-afectivos en un caso de autismo (Trabajo de grado no publicado). Corporación Universitaria Minuto de Dios, Bogotá, Colombia.

Cheshire, Leonard. (2019). Educación inclusiva para personas con discapacidades: ¿estamos logrando avances? Documento de discusión para el Foro Internacional sobre Equidad e Inclusión en la Educación. Todas y todos los estudiantes cuentan. Cali. Colombia. París: UNESCO.

Delgado, Vilma., y Moreno, Johanna Julieta. (2018). Propuesta de adaptaciones curriculares en el área de la lengua castellana para un estudiante de grado sexto con Trastorno del Espectro Autista (TEA) de una institución educativa de Bucaramanga (Trabajo de Maestría no publicado). Universidad Autónoma de Bucaramanga (UNAB), Bucaramanga, Colombia.

Departamento Nacional de Planeación (DNP). (2015). Lineamientos generales de flexibilización de la oferta para población víctima de violencia. Bogotá: Autor.

Díaz, Soley Marcela., y Álvarez, Marisol. (2016). Identificación de aspectos que influyen en el acceso, tránsito y socialización de estudiantes con autismo en la educación superior en Bogotá, D.C. (Trabajo de Especialización no publicado). Universidad Piloto de Colombia, Bogotá, Colombia.

Duarte, Luz Mila., Pabón, Nury Esther., Ascencio, Angélica María., y Gómez, Pedro Nel. (2019). Discapacidad visual. Una experiencia en el profesorado estatal del Departamento de Santander, Colombia. Nodos y Nudos, 6(46), 13-26.

Echeíta, Gerardo. (2019). Educación inclusiva. El sueño de una noche de verano. Barcelona: Octaedro.

Espinosa, Viviana. (2019). Inclusión y derecho a la educación de la comunidad LGBTI: Análisis de las representaciones sociales de docentes y estudiantes del programa de Administración en Seguridad y Salud en el Trabajo (ASST) - Uniminuto - Centro Regional Madrid (Trabajo de Maestría no publicado). Corporación Universitaria Minuto de Dios, Bogotá, Colombia. 
Fast, Jonathan. (2016). Más allá de la intimidación. ¿Cómo romper el ciclo de vergüenza, acoso y violencia? México: FCE.

Fernández, Flavio., y Duarte, Julio. (2016). Retos de la inclusión académica de personas con discapacidad en una universidad pública colombiana. Formación Universitaria, 9(4), 95104.

Fernández, Carmen., Fiuza, María J., y Zabalza, María Ainoha, (2013). A propósito de cómo analizar las barreras a la inclusión de la comunidad educativa. Revista de Investigación en Educación, 11(3), 172-191.

Fresneda, Angélica. (2019). Configuración de la autodeterminación desde las narrativas de personas con discapacidad intelectual (Trabajo de Maestría no publicado). Universidad Pedagógica Nacional, Bogotá, Colombia.

Galeano, Gabriela. (2018). Políticas educativas de inclusión y articulación y los programas educativos inclusivos de los casos de Chile y Colombia (Trabajo de grado de Maestría no publicado). Pontificia Universidad Católica de Chile, Santiago de Chile.

García, Karen Stefanny., y Martínez, Lizza Fernanda. (2019). Estrategias didácticas en un aula incluyente para el aprendizaje de los estudiantes con discapacidad intelectual del Jardín Infantil "Los Pingüinos" (Trabajo de grado no publicado). Fundación Universitaria Los Libertadores, Bogotá, Colombia.

González, Francisca., Martín, Elena., y Poy, Raquel. (2019). Educación inclusiva: Barreras y facilitadores para su desarrollo. Análisis de la percepción del profesorado. Profesorado. Revista de Currículum y formación del profesorado, 23(1), 243-263.

González, Yineida., y Triana, Dairo A. (2018). Actitudes de los docentes frente a la inclusión de estudiantes con necesidades educativas especiales. Educación y Educadores, 21(2), 200-218.

Granada, Maribel., Pomés, María Pilar., y Sanhueza, Susan. (2013). Actitud de los profesores hacia la inclusión educativa. Papeles de Trabajo, (25), 51-59.

Gutiérrez, Mario Fernando., y Martínez, Liliana. (2020). Representaciones sociales de docentes sobre la inclusión del estudiantado con discapacidad. Revista Electrónica de Investigación Educativa, 22(e13), 1-13.

Guzmán, Michelle Valeria. (2016). Diversidad sexual en una escuela pública en el Municipio de Jamundí (Trabajo de grado no publicado). Universidad de San Buenaventura, Cali, Colombia.

Jácome, Valentina., Pinilla, Valeria., y Rojas, María Fernanda. (2019). Inclusión educativa de personas con discapacidad visual propuestas desde la comunicación para el desarrollo. El caso de la IED República de China (Trabajo de grado no publicado). Universidad de La Sabana, Bogotá, Colombia. 
Laiton, Claudia Inés. (2018). Prácticas pedagógicas, la lectura como goce y la literatura como derecho para escolares con discapacidad intelectual (Trabajo de Maestría no publicado). Universidad Nacional de Colombia, Bogotá, Colombia.

Linares, Johana., Hernández, Andrea., y Rojas, Héctor Mauricio. (2019). Afrontamiento espacial de estudiantes con discapacidad física. Entramado, 15(2), 174-187.

López, Yessica Alejandra., Martínez, Angie Carolina., Negrete, Yiseth María., y Paternina, Saira Luz. (2016). Factores asociados a la homofobia en estudiantes de enfermería de las universidades de la ciudad de Cartagena (Tesis para optar por el título de Enfermera Profesional). Universidad de Cartagena, Cartagena, Colombia.

Madero, Julia del Rosario. (2017). Concepciones de los docentes de básica primaria sobre educación inclusiva en la institución educativa María Inmaculada de San Benito Abad Sucre - Colombia. Entornos, 30(2), 37-49.

Materón, Solangel. (2016). Principios de equidad e igualdad: Una perspectiva inclusiva para la atención educativa de las poblaciones con discapacidad en Colombia. Revista Colombiana de Bioética, 11(1), 117-131.

Marulanda, Elena., y García-Cepero, María Caridad. (2019). Educación inclusiva en la universidad. Más allá de la supervivencia del más fuerte. En Elena Marulanda (Ed.). Pedagogía, formación e innovación. Reflexiones de maestros para maestros (pp. 81102). Bogotá: Pontificia Universidad Javeriana.

Mayorga, Jessica Alejandra., y Sánchez, Diana Paola. (2018). Estrategias para la educación inclusiva en estudiantes con discapacidad cognitiva del Colegio Cristiano de Colombia y el Colegio Integral Avancemos (Trabajo de grado no publicado). Institución Universitaria Politécnico Grancolombiano, Bogotá, Colombia.

Mejía, Sandra Isabel. (2019). Diversidad funcional e inclusión en Instituciones de Educación Superior en Medellín. Interdisciplinaria, 36(2), 151-164.

Mella, Sandra., Díaz, Nicole., Muñóz Stephanie., Orrego, María., y Rivera, Carolina. (2014). Percepción de facilitadores, barreras y necesidades de apoyo de estudiantes con discapacidad en la Universidad de Chile. Revista Latinoamericana de Educación Inclusiva, 8(1), 63-80.

Ministerio de Educación Nacional (MEN). (2017a). Documento de orientaciones técnicas, administrativas y pedagógicas para la atención educativa a estudiantes con discapacidad en el marco de la educación inclusiva. Bogotá: Autor.

Ministerio de Educación Nacional (MEN). (2017b). Decreto 1421. Por el cual se reglamenta en el marco de la educación inclusiva la atención educativa a la población con discapacidad. Bogotá: Autor.

Ministerio de Educación Nacional (MEN). (2013). Ley 1620. Por la cual se reglamenta el Sistema Nacional de Convivencia Escolar y Formación para el Ejercicio de los Derechos 
Humanos, la Educación para la Sexualidad y la Prevención y Mitigación de la Violencia Escolar. Bogotá: Autor.

Ministerio de Interior de Colombia (2018). Decreto 762. Por el cual se adopta la Política Pública para la garantía del ejercicio efectivo de los derechos de las personas que hacen parte de los sectores sociales LGBTI y de personas con orientaciones sexuales e identidades de género diversas. Bogotá: Autor.

Molina, Rocío (2010). Educación superior para estudiantes con discapacidad. Revista de Investigación, 34(70), 109-128.

Montaño, Luz Mélida., Cerón, Johana Elizabeth., y Martín, Mario Andrés. (2019). Relación cooperativa entre docentes y padres de estudiantes con discapacidad. Magis, Revista Internacional de Investigación en Educación, 12(24), 145-160.

Morales, Elisa Yohana. (2018). Las voces de los y las adolescentes con discapacidad intelectual sobre sus experiencias de vida: Un análisis a sus procesos de autodeterminación en las prácticas escolares cotidianas (Trabajo de Maestría no publicado). Universidad Francisco José de Caldas, Bogotá, Colombia.

Morales, Maribel., y Borja, Deissy Johane. (2019). Estado del arte. Estrategias lúdicas y didácticas para población con discapacidad intelectual en la infancia y básica primaria (2010-2019) (Trabajo de grado no publicado). Universidad Pedagógica Nacional, Bogotá, Colombia.

Navarro, Pablo., y Díaz, Capitolina. (2007). Análisis de contenido. En Juan Manuel Delgado y Juan Gutiérrez (Coords.). Métodos y técnicas cualitativas de investigación en ciencias sociales (pp. 177-221). Madrid: Síntesis.

Ñaupas, Humberto., Mejía, Elías., Novoa, Eliana., y Villagómez, Alberto. (2014). Metodología de la investigación cualitativa y cuantitativa. Bogotá: Ediciones de la U.

Organización de las Naciones Unidas para la Educación, la Ciencia y la Cultura (UNESCO). (2015). Educación 2030: Declaración de Incheon y Marco de Acción para la realización del Objetivo Sostenible 4. París: Autor.

Organización de las Naciones Unidas para la Educación, la Ciencia y la Cultura (UNESCO). (2019). Foro Internacional sobre Equidad e Inclusión en la Educación. Todas y todos los estudiantes cuentan. Cali: Autor.

Paredes, Francisco Javier. (2019). Educación inclusiva y calidad de vida en estudiantes con Trastorno del Espectro Autista (TEA). Orientaciones para el abordaje en el nivel de básica primaria (Trabajo de Maestría no publicado). Universidad Nacional de Colombia, Bogotá, Colombia.

Parrado, Jennifer Julieth. (2020). Experiencias y procesos de subjetivación de estudiantes con discapacidad intelectual en procesos de inclusión educativa (Trabajo de Maestría no publicado). Universidad Pedagógica Nacional, Bogotá, Colombia. 
Pinilla, Fabio Alejandro. (2017). Propuesta para la erradicación del matoneo y el fomento del respeto de la diversidad sexual en las aulas escolares colombianas (Trabajo de Especialización no publicado). Universidad Militar Nueva Granada, Bogotá, Colombia.

Polo, Néstor David. (2018). Ser e interactuar: Prácticas comunicativas de los grupos universitarios LGBTI en Bogotá (Cátedra UNESCO de comunicación: Comunicación, lenguajes, TIC e interculturalidad. Numeral 6.2.: Feminismos, masculinidades, género y comunicación). Bogotá: UNESCO.

Posada, Diego Bernardo. (2019). La emergencia de la ideología de género en Colombia: Preferir un hijo muerto que marica. Cuadernos de música, artes visuales y artes escénicas, 14(2), 75-101.

Quiceno, Gisela., y Mora, Caterine. (2016). Exclusión de la población LGBTI en Trabajo Social (Trabajo de grado no publicado). Corporación Universitaria Minuto de Dios, Bogotá, Colombia.

Ramírez, Camila., Torrado, Ana Karina., y Villegas, Valeria. (2018). Educación sexual diversa e incluyente. Una necesidad para la juventud colombiana (Trabajo de grado para optar por el título de Psicología). Pontificia Universidad Javeriana, Bogotá, Colombia.

Ramírez, Fidel Mauricio. (2017). Inclusión educativa de estudiantes sexualmente diversos en Colombia, periodo 2000-2015. Comprensiones pedagógicas de las sentencias de la Corte Constitucional (Tesis doctoral). Universidad Santo Tomás, Bogotá, Colombia.

Ramírez, Fidel Mauricio. (2018). Discursos, silencios, violencias y prácticas educativas en torno a estudiantes con orientaciones sexuales e identidades de género diversas. Polisemia, 14(25), 83-92.

Ramírez, Fidel Mauricio., y Cardona, Jeison Andrés. (2020). Discursos, prácticas y temáticas de maestros y maestras en primera infancia acerca de la diversidad sexual y de género: Límites y posibilidades para la consolidación de una educación inclusiva. Revista Interamericana de Investigación, Educación y Pedagogía, 13(2), 59-81.

Rivas, José I., Leite Analía E., y Prados, Esther (Coords.). (2014). Profesorado, escuela y diversidad. La realidad educativa desde una miarad narrativa. Málaga: Aljibe.

Rodríguez, Alba Nubia., y Rivera, Janet del Carmen. (2020). Diversidades sexuales e identidades de género: Entre la aceptación y el reconocimiento. Instituciones de Educación Superior. Revista CS, (31), 327-357.

Rodríguez, Paola Andrea. (2018). Narrativas de los sujetos con discapacidad intelectual y sus aportes a la construcción de subjetividades en escenarios educativos (Trabajo de Maestría no publicado). Universidad Pedagógica Nacional, Bogotá, Colombia.

Rodríguez, Sandra Liliana. (2020). Sistematización de la experiencia "Inclusión" realizada entre 2010 y 2014 en el Colegio Nueva Colombia IED de la localidad de Suba (Trabajo de Maestría no publicado). Universidad Pedagógica Nacional, Bogotá, Colombia. 
Rodríguez, Victoria Alejandra. (2020). Coeducación: Aproximación a una epistemología feminista en el aula. Revista de Estudios de Género, La Ventana, (51), 32-52.

Romero, Karen Milena. (2019). Observación científica como estrategia pedagógica para la enseñanza y el aprendizaje de la biodiversidad colombiana en estudiantes con discapacidad múltiples (visual e intelectual) del aula de apoyo pedagógico de la institución educativa distrital República de China (Trabajo de grado no publicado). Universidad Pedagógica Nacional, Bogotá, Colombia.

Romero, María Fernanda., y Urrego, Sara. (2016). Inclusión de personas con discapacidad sensorial (ciegos y sordos) en los procesos de formación musical universitaria en la ciudad de Bogotá, D.C. Uni-pluri/versidad, 16(2), 27-40.

Sanjuanelo, Alexandra., Jiménez, Luz Mabel., y Rodas, Melisa. (2016). Sistematización de investigaciones recientes y pertinentes del tema LGBTI en el ámbito educativo (Trabajo de grado no publicado). Corporación Universitaria Adventista, Medellín, Colombia.

Slee, Roger. (2012). La escuela extraordinaria. Exclusión, escolarización y educación inclusiva. Madrid: Morata.

Tárraga, Raúl., Grau, Claudia., y Peirats, José. (2013). Actitudes de los estudiantes de Grado de Magisterio y del Máster de Educación especial hacia la inclusión educativa. Revista Electrónica Interuniversitaria de Formación del Profesorado, 16(1), 55-72.

Tenorio, Solange., y Ramírez, María José. (2016). Experiencia de inclusión en educación superior de estudiantes en situación de discapacidad sensorial. Educación y Educadores, 19(1), 9-28.

Urrútia, Gerard., y Bonfill, Xavier. (2010). Declaración PRISMA: Una propuesta para mejorar la publicación de revisiones sistemáticas y meta-analyses. Medicina Clínica, 135(11), 507-511.

Vesga, Luz del Sol., Pisso, Luz Betty., y Villaquirán, Diana Carolina. (2016). Exclusión escolar: Caso de una niña con parálisis cerebral en una institución educativa urbana marginal de Popayán. Revista Katharsis, (21), 217-240.

Victoriano, Eugenia. (2017). Facilitadores y barreras del proceso de inclusión en educación superior: La percepción de los tutores del programa Piane-UC. Estudios Psicológicos, 43(1), 349-369.

Zambrano, Christian., Hernández, Pahola., y Guerrero, Alejandra. (2019). Procesos de reconocimiento de la orientación sexual homosexual en estudiantes de una universidad pública. Psicogente, 22(41), 1-29.

Zúñiga, Sandra, e Hincapié, Olga Lucía (2021, en prensa). Barreras físicas percibidas por estudiantes de una institución universitaria de la ciudad de Cali frente a la discapacidad. Rehabilitación (Madr), 55(1), 22-29. DOI: 10.1016/j.rh.2020.05.006 
Revista indizada en

sciplo

redalyc latindex

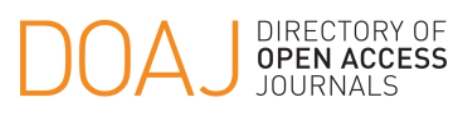

Distribuida en las bases de datos:

- Dialnet

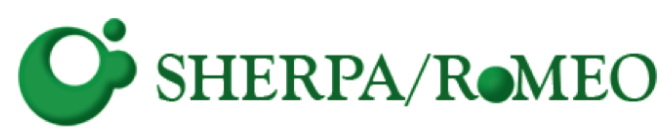

REDIB

Red Iberoamericana

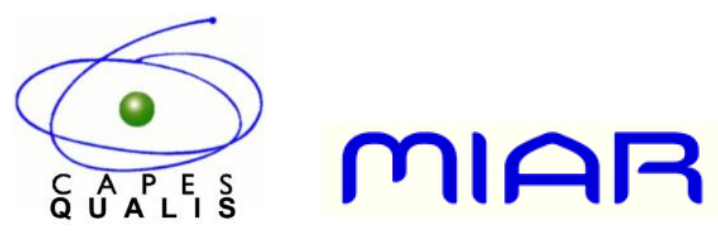

